\title{
El Instituto Filarmónico del Conde de Morphy y su Escuela de Canto en el establecimiento del drama lírico nacional ${ }^{1}$
}

\author{
The Philharmonic Institute of the Count of \\ Morphy and his Singing School in the \\ Establishment of National Lyric Drama
}

A finales de 1883, una serie de músicos, que compartían unas mismas inquietudes respecto a la regeneración del arte español, se reúnen en sociedad para fundar el Instituto Filarmónico en Madrid, ofreciendo una formación musical a la altura de otros centros europeos. Se muestra en este trabajo a los individuos que, liderados por el Conde de Morphy, formaron parte de la Sociedad del Instituto, y su importante papel en la lucha por el arte nacional. Se resalta el carácter regenerador de su proyecto educativo en comparación a las enseñanzas del Conservatorio de Madrid. Especialmente la escuela de canto lírico regentada por Napoleón Verger contribuyó a elevar el nivel de canto en España, y a dotar a los escenarios líricos con figuras de renombre, facilitando el camino al establecimiento del drama lírico nacional.

Palabras clave: Instituto Filarmónico, Conservatorio, enseñanza musical, el Conde de Morphy, Napoleón Verger, ópera nacional.

In late 1883, a number of musicians, sharing the same concerns regarding the regeneration of Spanish art, gathered together in a society in Madrid to found the Philharmonic Institute with the aim of offering musical training at the same level as other European centres. This article examines the individuals who, led by Count Morphy, participated in the Institute, and analyses their significant role in the struggle for a national art form. The regenerative nature of their educational project, compared to the teachings of the Conservatory of Madrid, is highlighted. In particular, the bel canto school run by Napoleón Verger helped to improve the standard of singing in Spain and to endow opera stages with renowned figures, thus paving the way for the establishment of Spanish lyric drama.

Keywords: Philharmonic Institute, Conservatory, music education, Count Morphy, Napoleón Verger.

El Conservatorio de Madrid bajo la dirección de Arrieta. Las críticas a una enseñanza obsoleta

En el siglo XIX la influencia del Conservatorio de Madrid en la sociedad española creció impulsada por los nuevos gustos de la burguesía

${ }^{1}$ Este trabajo forma parte de mi tesis doctoral sobre Guillermo Morphy (1836-1899), Conde de Morphy, dirigida por Ramón Sobrino Sánchez (Universidad de Oviedo), a quien agradezco la revisión del presente artículo. 
romántica. Sin embargo, la Escuela Nacional de Música y Declamación, dirigida por Emilio Arrieta desde 1868, que se regía por un reglamento obsoleto, no logró modernizar sus enseñanzas y atender a las necesidades de su profesionalización al modo de otros centros europeos ${ }^{2}$. La institución funcionaba como centro de "propaganda musical", que satisfacía preferentemente a un alumnado aficionado ${ }^{3}$. No existía una división de las enseñanzas entre elementales y superiores para separar los intereses del creciente grupo de amateurs, de aquéllos que realmente buscaban una salida profesional a sus estudios, en orquestas o teatros de ópera ${ }^{4}$. Figuras destacadas como Giner de los Ríos o Jimeno de Lerma criticaban la falta de una formación integral del alumno ${ }^{5}$. Además, se denunciaba la orientación claramente italianizante de las enseñanzas de canto, indiferentes hacia la cultura artística española, máxime cuando el Conservatorio había recibido el nombre de Escuela Nacional de Música y Declamación.

En un lapso de seis años -desde 1878 a 1884- el Conservatorio había casi duplicado el número de matrículas oficiales, pasando de 1218 a 2190 alumnos. Sin embargo, la dotación económica destinada al centro se había reducido notoriamente ${ }^{6}$. La falta de recursos provocaba aulas masificadas y

\footnotetext{
2 Emilio Arrieta (1821-1894) estuvo al frente del Conservatorio desde 1868 hasta 1894. Bajo su dirección el centro recibió el nombre de Escuela Nacional de Música y Declamación.

${ }^{3}$ El término fue acunado por Arrieta -según palabras de Bretón-, quien para defenderse de las críticas, consideraba el Conservatorio "como centro de propaganda más bien que de enseñanza superior" debido a su numerosa matrícula, en Memoria precedida del discurso de Tomás Bretón. 1900-1901, Madrid, Imp. Ducazcal, 1901, p. 7.

${ }^{4}$ A ello hace referencia Rafael Taboada en su estudio crítico sobre el Conservatorio, donde defiende que "para que la Escuela Nacional de Música logre adquirir una organización que corresponda al desarrollo que el arte ha tomado en España, es necesario, [...] separar la enseñanza elemental de la superior, facilitando el ingreso en la Escuela para la primera y dotando de un número fijo de alumnos la segunda, en cuyas aulas no puedan ingresar sin previa oposición los que aspiren a hacerlo, como sucede en los principales Conservatorios de Europa". Véase Rafael Taboada y Mantilla: "La Escuela Nacional de Música y Declamación", Madrid, Establecimiento tipográfico de Ricardo Álvarez, 1890, p. 8.

5 En 1878 Giner de los Ríos, integrante de la Institución Libre de Enseñanza, ataca duramente al Conservatorio y reclama la inclusión de asignaturas como Historia de la Música, Estética y del Arte dentro de su plan de estudios. Su interés por la educación de los músicos profesionales le lleva a plantearse, en 1886, la creación de una Escuela de Música en la sección de estudios superiores del Instituto Libre de Enseñanza, que nunca llegó a materiarizarse. Véase Leticia Sánchez de Andrés: "El pensamiento y la actividad musical de Francisco Giner de los Ríos", Francisco Giner de los Ríos: actualidad de un pensador Krausista, Madrid, Marcial Pons Historia, 2009, p. 248. Sobre las críticas al Conservatorio bajo la dirección de Arrieta, véase María Encina Cortizo: Emilio Arrieta. De la ópera a la zarzuela, Madrid, ICCMU, 1998. Años más tarde se suma a las críticas Idelfonso J. de Lerma, quien, refiriéndose a los músicos, escribe: "[...] es indispensable que amplíen sus conocimientos meramente técnicos con otros de estética, historia crítica y bibliografía musical [...]. Asimismo juzgo que convendría dividir la enseñanza oficial del divino arte en dos grandes ramas: la común y la superior", Discursos leídos ante la real academia de Bellas Artes de San Fernando en la recepción Pública del Sr. D. Idelfonso Jimeno de Lerma, Madrid, Imp. y Fundición de Manuel Tello, 1883, p. 47.

${ }^{6}$ Datos obtenidos en María Encina Cortizo: Emilio Arrieta..., p. 455.
} 
mezcla de niveles en una misma clase $e^{7}$, viéndose obligada una parte del alumnado a recurrir a las clases particulares ${ }^{8}$ para suplir la falta de calidad en la enseñanza del centro. Otras críticas se dirigen al excesivo número de premios y a las altas calificaciones por parte de los profesores, además del problema de las "recomendaciones", mediante las cuales se buscaba un trato de favor a la hora de calificar los exámenes de los alumnos. Los efectos perniciosos de esta práctica habitual en España eran señalados por el director general de Instrucción pública J. Xiquena al afirmar que "contribuye a sostener la holganza de los malos estudiantes, acostumbra a los alumnos a esperarlo todo a su favor, no de su aptitud y constancia en el trabajo, y enerva la energía de los aplicados al considerar la energía con que se les igualan en títulos los indolentes e ineptos" 9 .

En los años que rodean la creación del Instituto Filarmónico, arrecian las críticas contra Arrieta, demandando la modernización del centro. En febrero de 1884, Montes de Ayala denuncia en El Arte la falta de preparación de las alumnas de canto del Conservatorio, tras sus fracasos en el $\mathrm{Real}^{10}$. Aún más radicales son los artículos firmados en septiembre de 1886 bajo el seudónimo del "Maestro de música" y publicados en La Opinión, en los que se menciona la conveniencia de cerrar un Conservatorio "ineficaz e improductivo"11. En el mismo tono, "Lucrecio Mestón" denuncia el carácter amateur del centro, reiterando la necesidad de convertirlo en un centro superior ${ }^{12}$. A estas críticas se suma Tomás Bretón, si bien en un tono menos radical ${ }^{13}$.

En este contexto en el que se alzan voces pidiendo una renovación pedagógica de las enseñanzas del Conservatorio, se sitúan las propuestas regeneracionistas del Conde de Morphy ${ }^{14}$. En 1894, tras la muerte de

${ }^{7}$ A las clases de Solfeo, que se hacían en tres años, asistían los alumnos de diferentes cursos a una misma aula, dificultando la enseñanza "hasta el extremo de hacerla imposible", en R. Taboada Mantilla: "La Escuela...", pp. 8-9.

${ }^{8}$ Ibid., p. 9.

${ }^{9}$ Entre las escasas reformas acometidas por el Ministerio y aplaudidas por Arrieta está la aprobación en 1889 de una serie de disposiciones contra la "recomendación". De escasos resultados, será uno de los principales problemas al que se enfrentará Tomás Bretón como director al frente del Conservatorio. Gaceta de Madrid, n. ${ }^{\circ}$ 143, 23 de mayo de 1889, p. 572.

10 "[...] si las alumnas del Conservatorio no han obtenido los éxitos deseados en sus sucesivos debuts en el Real esto se debe a que la enseñanza de dicha disciplina en el centro es mala, y no ofrece los profesionales adecuados", Montes de Ayala: El Arte, año III, n. ${ }^{\circ}$ 68, 4-II-1884. Citado en M. E. Cortizo: Emilio Arrieta..., pp. 455-456.

${ }^{11}$ Citado en Victor Sánchez: Tomás Bretón. Un músico de la Restauración, Madrid, ICCMU, 2002, p. 139

${ }^{12}$ Mestón: "Algo sobre el Conservatorio", El Arte, año IV, n. ${ }^{\circ}$ 122, 30-VI-1885. Referido en M. E. Cortizo: Emilio Arrieta..., pp. 456-458.

${ }^{13}$ Véase V. Sánchez: Tomás Bretón..., pp. 138-139.

${ }^{14}$ Guillermo Morphy (1836-1899), musicógrafo, compositor y crítico musical, fue secretario de Alfonso XII y posteriormente de la reina regente María Cristina. Estuvo involucrado en las instituciones 
Arrieta, el Ministerio de Fomento encarga al Conde de Morphy formar parte de una Comisión para impulsar las reformas que debería acometer el Conservatorio de Madrid ${ }^{15}$. Profundo conocedor de los conservatorios extranjeros por su propia experiencia vital, propone, por un lado, la profesionalización del Conservatorio al modo de otras escuelas de perfeccionamiento como las de Bélgica, Alemania, Austria y Francia, con la obligación de un examen de ingreso para los alumnos, de Bachiller de música, y, por otro, la creación de escuelas de música encargadas de las enseñanzas elementales. Asimismo, reivindica la necesidad de incluir la asignatura de música dentro de las escuelas primarias ${ }^{16}$.

No cabe duda de que el inmovilismo que manifestó Arrieta, junto con el gobierno, para llevar a cabo reformas significativas durante la Restauración, unido a la carencia de otros centros de enseñanza musical en Madrid, impulsaron la creación del Instituto Filarmónico, que no sólo atendió al creciente número de dilettanti, sino que además ofreció enseñanzas de perfeccionamiento a los alumnos que finalizaban sus estudios en el Conservatorio. El Instituto fue capaz de ofrecer con éxito un modelo de enseñanza a la altura de otros conservatorios europeos, sirviendo de precedente a los cambios que, años más tarde, adoptaría el Conservatorio de Madrid.

\section{Un centro de libre enseñanza en Madrid: el Instituto Filarmónico ${ }^{17}$}

\section{Precedentes del Instituto Filarmónico}

Dentro del asociacionismo musical con finalidad instructiva del siglo XIX, entre las entidades que por su relevancia y cercanía en el tiempo

más representativas de la música, en Madrid: presidente de la Sociedad de Conciertos (1884-1890), coincidiendo con Tomás Bretón como director, presidente de la Sección de Bellas Artes del Ateneo (1886-1895) y académico de número de la Sección de Música, en la Academia de Bellas Artes de San Fernando. Respetado por su amplia cultura, sólida formación musical y su lucha constante por establecer la ópera nacional, ejerce un intenso mecenazgo y se preocupa por prestar su apoyo a toda una generación de jóvenes músicos, entre los que destacan Pablo Casals, Isaac Albéniz y Tomás Bretón. En relación a Morphy, véase Ramón Sobrino: "El Conde de Morphy (1836-1899), protagonista musical de una época. Epistolarios a Albéniz y Pedrell”, Cuadernos de Música Iberoamericana, vol. 7, 1999, pp. 61-102. También los trabajos publicados por Pepe Rey: "Guillermo Morphy: el redescubrimiento de la vihuela en el siglo XIX. I. París, 1868-1870", Roseta, 3, 2009, pp. 26-45; id.: "Guillermo Morphy: el redescubrimiento de la vihuela en el siglo XIX. II. Madrid, 1875-1899", Roseta, 4, 2010, pp. 46-61.

${ }^{15}$ Gaceta de Madrid, n. ${ }^{\circ}$ 159, 8-VI-1894. La Comisión estaría formada por el Conde de Morphy, junto a Tomás Bretón, Gaspar Núñez de Arce, Manuel Tamayo y Baus, Gabriel Rodríguez y Gabriel Balart.

${ }^{16}$ G. Morphy: "Revista Musical", La España Moderna, año VI, tomo LXXI, noviembre de 1894, p. 156.

${ }_{17}$ Beatriz Alonso Perez-Ávila, en su tesis sobre El compositor Emilio Serrano y Ruiz, incluye un estudio sobre el Instituto Filarmónico, a cuyo contenido no se ha tenido acceso por tratarse de una tesis inédita. Según comunicación personal de la autora se trata de un estudio genérico sobre la entidad. Beatriz Alonso Perez-Ávila: El compositor Emilio Serrano y Ruiz (1850-1939): su compromiso regeneracionista con las instituciones del Madrid coetáneo. Estudio analítico de su producción instrumental y sinfónica, tesis doctoral dirigida por María Encina Cortizo, presentada en la Universidad de Oviedo en diciembre de 2015. 
pudieron influir en el Conde de Morphy a la hora de impulsar el proyecto educativo del Instituto Filarmónico, cabe destacar la Academia Filarmónica de Sevilla, creada en 1882, y dirigida por Luis Leandro Mariani ${ }^{18}$, que pasaría a ser Conservatorio de Música en 1894. Esta academia tiene su precedente en el Instituto de Música y Declamación de Sevilla, surgido en el seno de su Sociedad Filarmónica, por iniciativa de su presidente, el Conde del Águila, y cuya actividad se extinguió en el cuso 1864-65 por falta de subvenciones. Por otro lado, destaca el prestigioso Instituto Filarmónico de Santa Cecilia en Cádiz ${ }^{19}$, que además de ofrecer una enseñanza al alcance de las clases populares, impartía formación profesional a sus alumnos. El Instituto estaba dirigida por Luis Odero ${ }^{20}$ y presidido en la década de los ochenta por Luis Terry Murphy, primo carnal del Conde de Morphy ${ }^{21}$. Tanto el rey Alfonso XII como el Conde de Morphy fueron nombrados socios honorarios del mismo ${ }^{22}$.

En Madrid, debe mencionarse la prestigiosa Escuela Lírico-Dramática creada por Antonio Cordero y Juan Jiménez en 1866, cuyo objetivo era impulsar la ópera española. Entre sus alumnos contó con destacados cantantes, como el famoso tenor Julián Gayarre ${ }^{23}$. Sin embargo, en la época que nos ocupa, El Liberal señala, con motivo de la fundación del Instituto Filarmónico, la ausencia de escuelas o academias de música como vías alternativas al Conservatorio de Madrid:

En Madrid se nota la falta de algunos centros artísticos que ayuden a difundir la enseñanza de la música, respondiendo a las verdaderas necesidades del arte y a la creciente afición que por él se ha despertado en todas las clases sociales. Por esta

\footnotetext{
${ }^{18}$ Véase Andrés Vallés Chordá: "Orígenes, crecimiento y fracaso de la Sociedad Filarmónica de Sevilla”, Anuario GRHIAL, n. ${ }^{\circ}$ 1, Universidad de los Andes, Mérida, 2007, pp. 47-54. También el más reciente de Olimpia García López: "La recompensa a un esfuerzo colectivo: el nacimiento del Conservatorio de Música de Sevilla", Diferencias. Revista del CSM Manuel Castillo de Sevilla, 3. ${ }^{a}$ época, n. ${ }^{\circ}$, 2014, pp. 119-150.

${ }_{19}$ Este Instituto nace en el seno de la Academia de Santa Cecilia, fundada en 1859 y sustentada, a partir de 1862, con subvenciones del Ayuntamiento y de la Diputación. Sobre la misma puede consultarse Diego Navarro Mota: La historia del Conservatorio de Cádiz en sus documentos, Cádiz, Instituto de Estudios Gaditanos, 1976.

${ }^{20}$ El Guadalete, año XXXI, n. ${ }^{\circ} 9046,20-I X-1885$, p. 2.

${ }^{21}$ Si bien Guillermo Morphy nació en Madrid, su familia de linaje irlandés se estableció en Cádiz a finales del siglo XVII, donde algunos de sus descendientes establecieron vínculos de parentesco con los Terry, según consta en el archivo familiar de la autora. Algunas ramas de esta familia utilizan el apellido Murphy en vez de Morphy.

${ }_{22}$ El centro había sido conocido por Morphy en ocasión de un viaje realizado a Cádiz, junto al Rey Alfonso XII, el 24 de marzo de 1877. Por este motivo, el Casino Gaditano ofreció un concierto organizado por el Instituto Filarmónico, en el que se estrenó la Sonatina española a cuatro manos compuesta por Morphy, José Bruna: Impresiones de un viaje a Andalucía con S. M. el Rey Don Alfonso XII, Madrid, Imp. Estereotipa y Galvanop, 1877, p. 105.

${ }^{23}$ María del Coral Morales Villar: Los tratados de canto en España durante el s. XIX, tesis doctoral, Granada, Universidad de Granada, 2008, pp. 697-704.
} 
razón merece todo tipo de elogios el pensamiento de los distintos profesores que se han asociado para fundar lo que podríamos llamar una escuela libre de música, y ellos llaman modestamente Instituto Filarmónico ${ }^{24}$.

El 2 de febrero de 1884 Morphy organiza un banquete en el restaurante Los Dos Cisnes, al que asisten artistas y periodistas de El Imparcial, El Estandarte, El Cronista, El Diario Español, La Correspondencia y La Época, anunciando "la creación de una escuela libre de música para dar enseñanza a cuantos jóvenes se sienten inclinados a cultivar aquel arte, y donde los que salen del conservatorio puedan desenvolver sus aptitudes, dando a conocer sus adelantos" 25 . De este modo nace el Instituto Filarmónico, cuyas clases tendrían lugar en la calle Esparteros, número 3, con el objetivo de llevar la música a todas las clases sociales ${ }^{26}$.

Tomás Bretón, que conoce su proyecto educativo, escribe en su Diario, el 15 de marzo de 1884, sobre el alcance "inmenso" que involucraba la creación del Instituto y su similitud con la Sociedad de Amigos de la Música en Viena, la Gesellschaft der Musikfreunde:

Recibí una carta interesantísima del señor Conde en la que me da detalles de la Academia que preside, la cual es de ¡un alcance inmenso! una especie de Gessellschaft der Musikfreunde [...]. Piensa hacer local propio, con salón de conciertos, establecer la Opera Nacional; entusiasmado, loco de alegría, presa de una ilusión le he escrito que allí estoy yo donde sea necesario, que la realización de tal plan le hará inmortal en nuestra patria ¡bravo por el Conde!, hará un beneficio al Arte imperecedero $^{27}$.

La Gessellschaft der Musikfreunde, referida por Bretón, había sido fundada en Viena, en 1812, por Joseph von Sonnleithner, secretario general del Court Theatre de Viena. Su objetivo era el fomento de la música en todos sus ámbitos, atendiendo a su divulgación mediante conciertos y, asimismo, la enseñanza musical a través de la Academia de Música, en la que llegarían a estudiar importantes músicos como Gustav Mahler, Leos Janacek, Hugo Wolf y Anton Bruckner, entre otros ${ }^{28}$.

24 "Instituto Filarmónico", El Liberal, año VI, n. ${ }^{\circ} 1667$, 5-II-1884, p. 2.

${ }^{25}$ El Imparcial, año XVIII, n. ${ }^{\circ} 5989$, 3-II-1884, p. 3.

26 Diario de Córdoba, año XXXV, n. ${ }^{\circ} 10188,6-$-II-1884, p. 2.

${ }^{27}$ T. Bretón: Diario, vol. 1, ed., estudio e índice de Jacinto Torres Mulas, Madrid, Acento editorial, 1994. p. 353. A Guillermo Morphy le unía una gran amistad con Tomás Bretón, ya que ambos compartían el ideal de establecer la ópera nacional. El Conde veía en Bretón la persona capaz de llevar a cabo semejante propósito.

${ }^{28}$ La institución vienesa es mencionada por Luisa Lacal en la voz "Conservatorio", donde incluye un somero estudio de las instituciones de enseñanza más destacadas fuera y dentro de España. L. Lacal: Diccionario de la música, Madrid, Est. tip. de San Francisco de Sales, 1900, pp. 133-135. 


\section{La Sociedad del Instituto Filarmónico ${ }^{29}$}

El 22 de diciembre 1883 se crea el Instituto Filarmónico en base a los estatutos firmados por el Conde de Morphy y veinte artistas más, que unidos en sociedad pasan a ser socios fundadores y muchos de ellos serán profesores del mismo: Natividad Cabañas, Pilar V. del Saco, Ruperto Cancio, Emilio Serrano, Agustín Rubio, Ricardo Oyanarte, Pedro de Urrutia, Cruz Cerezo, Melecio Brull, Apolinar Brull, Juan de Castro, Antonio Trueba, Carlos Saco del Valle, Luis Ramos, Ramón Michelena, Napoleón Verger, Luis Samaniego, Florencio Larrauri y Pantaleón Martínez ${ }^{30}$.

La asociación nace con el objetivo de "difundir la enseñanza de la música, propagando el conocimiento de sus bellezas y de su historia" ${ }^{1}$. Los socios fundadores se comprometían a sostener el Instituto con una suma de 300 pesetas, hasta que este pudiera mantenerse por sí mismo, siendo los únicos propietarios de los útiles, fondos y beneficios del mismo. Según el artículo 4 de los estatutos, aquellos socios que se encargaran de la enseñanza recibirían "una remuneración proporcionada a los beneficios que obtenga la Institución, sin perjuicio de sus derechos como socios fundadores" 32 . A su vez, el Instituto Filarmónico se constituía con dos órganos, por un lado, la Junta Directiva ${ }^{33}$ para el gobierno y administración del Instituto, y por otro la Junta General de Socios. Esta última, era la responsable de nombrar los cargos de la Junta Directiva, quedando constituida en 1883 por el Conde de Morphy (presidente), Emilio Serrano y Ruiz (vicepresidente), Carlos Saco del Valle (secretario), Apolinar Brull (tesorero) y Ruperto Cancio (contador). Dos años más tarde, el 25 de diciembre de 1885, la ausencia de Emilio Serrano ${ }^{34}$ y Saco delValle motiva que Ruperto Cancio pase a ser vicepresidente y secretario, y Antonio Trueba, contador.

${ }^{29}$ Todos los datos utilizados en el presente trabajo son extraídos del Archivo Histórico Nacional (AHN), Nobleza, Archivo Michelena, C.2, D. 96-104, donde se encuentran los documentos: Expediente de nombramiento de Ramón de Michelena y Padrés, I Conde de Michelena, como socio fundador del Instituto Filarmónico por parte del Conde de Morphy, Estatutos del Instituto Filarmónico y Memoria de sus actividades correspondientes a los cursos 1883-84, 1884-85 y 1885-86. Asimismo, algunas de estas memorias también pueden consultarse en la Biblioteca Histórica Municipal de Madrid, signaturas F 439, F 1212, F 1213, F 1214.

${ }^{30}$ Estatutos del Instituto Filarmónico, Madrid, Imp. de José M. Ducazcal, 1884, p. 7.

${ }^{31}$ Ibid., p. 3.

32 Ibid., p. 4.

${ }^{33}$ Entre los cometidos de la Junta directiva estaban: 1. Convocar a la General de Socios una vez al año sin perjuicio de reunirla cuando lo considere necesario. 2. Llevar la dirección y administración del Instituto, adoptando cuantas disposiciones estime oportunas para la marcha, fomento y prosperidad de sus fines. 3 . Nombrar, a propuesta del director, los profesores, sean o no socios fundadores, que se hayan de dedicar a la enseñanza y señalar la remumeración que les corresponda. 4. Determinar las cuotas con que han de contribuir los Socios fundadores, avisándolo siempre con ocho días de anticipación por lo menos. 5. Acordar la distribución de beneficios que permita el estado y las necesidades de la Asociación.

${ }^{34}$ El 8 mayo de 1885, Emilio Serrano solicita la plaza de pensionado de mérito al Ministerio del Estado que se haya vacante en la Academia de Bellas Artes, Actas de la Academia de Bellas Artes, Madrid, Fol. $123(8-\mathrm{V}-1885)$. 
El Instituto Filarmónico comenzó sus clases en enero de 1884 con un éxito fuera de todo lo previsible, viéndose en la necesidad de llamar a otros "profesores para todas las enseñanzas de la música, pues el número de los fundadores era insuficiente para las necesidades que habían de seguir" 35 . De este modo, se incorporaron inmediatamente los 21 profesores que constaban en el extracto del Reglamento interior del Instituto, entre ellos figuras tan destacadas como Isaac Albéniz, Enrique Fernández Arbós ${ }^{36}$, además deVicenta Tormo, Rosario Mendizabal, Cayetano Fernández, Ricardo Fernández, Enrique Calvist, Luis Lucientes, Manuel Lucientes, Francisco González Maestre, José Campra, Fermín Ruiz de Escobes, Alfonso Sotillo, Antonio Duque, José Valderrama, Casimiro Espino, Francisco Amato, Casto Vilar, Joaquín Valverde, Justo Blasco y Antonio Oller. Más tarde ingresaron para las clases de solfeo y piano:Valentín Arín, Javier Jiménez Delgado, Salvador S. Bustamante, Florencio Larrauri, Cándido Peña, Aguirre y José Estarrona $^{37}$. En la Memoria escrita por Ruperto Cancio, el 24 de octubre de 1886, se da las gracias a Isaac Albéniz, Jiménez Delgado y Tomás Bretón por contribuir al prestigio del Instituto ${ }^{38}$.

La entidad llegaría a contar con 84 artistas, entre socios fundadores y profesores pertenecientes al Claustro, quienes unidos en sociedad constituían una fuerza social ante el decadente panorama musical. Entre ellos cabe mencionar la presencia de destacados músicos de la Sociedad de Conciertos matritense, que desde diciembre de 1884 era presidida por Morphy y dirigida por su protegido Tomás Bretón ${ }^{39}$ : Manuel Âlvarez, Manuel Calvo, Juan de Castro, Ernesto Calvist, Antonio Cuéllar, Antonio Duque, Salvador Feijas, Ricardo Fernández, Rafael Gálvez, Manuel García, Francisco González Maestre, Andres Goñi, Manuel Jiménez, Luis Lucientes, Emilio Magesté, Alfonso Sotillo, Pedro de Urrutia, José Valderrama y FranciscoVidal ${ }^{40}$.

\footnotetext{
${ }^{35}$ Memoria del Instituto Filarmónico, 1883-1884, Madrid, Ducazcal, 1884, p. 6.

${ }^{36}$ La permanencia de Arbós en el Instituto fue escasa, pues, según apunta T. Bretón, op. cit., p. 385 , en abril de 1884 viaja con destino a Berlín, donde permanece hasta 1888, fecha en que vuelve a Madrid y obtiene la plaza de violinista en el Conservatorio. Arbós se refiere a este periodo de su vida: "como pedagogo era una completa nulidad, habiendo de limitarme exclusivamente a la demostración visual y auditiva". En: Enrique Fernández Arbós: Memorias de Arbós, Ed. Alpuerto, p. 236. En el caso de Albéniz, tras abandonar Barcelona en 1885 debido a dificultades económicas, se establece en Madrid, donde -según palabras de Pedrell- "su indiscutible talento y la protección del Sr. Conde de Morphy le proporcionan lecciones para atender a sus necesidades", Felipe Pedrell: Revista de Gerona, año XIV, n. ${ }^{\circ}$, mayo 1889, p. 138. Albéniz abandonará Madrid a finales de 1889, viajando al extranjero. Allí prosigue su vida concertística y se dedica a componer música para el teatro lírico.

${ }^{37}$ Memoria del Instituto Filarmónico. 1883-1884..., p. 6.

${ }^{38}$ Memoria presentada por la junta directiva 1885-1886, Madrid, Imp. José M. Ducazcal, 1886, p. 8.

39 Bretón colaborará con las actividades del centro como director de la orquesta del Instituto Filarmónico. Durante el curso 1884-85 es nombrado profesor honorario del Instituto Filarmónico, Memoria del Instituto Filarmónico, 1884-1885, Madrid, Imp. Ducazcal, 1885, p. 5.

${ }^{40}$ Datos del Archivo Real Conservatorio Superior de Música de Madrid (RCSMM), Actas de la Sociedad de Conciertos de Madrid, Libro $3^{\circ}$, n. $^{\circ} 659$.
} 
Además, el centro contaba con un gran número de compositores relevantes, que podemos clasificar en dos grupos. Un primer grupo, cuyo nacimiento tendría lugar en torno a 1840: Guillermo Morphy (1836), Oscar de la Cinna (1836), Casimiro Espino (1845), Apolinar Brull (1845), Joaquín Valverde (1846) y Varela Silvari (1848) y Jiménez Delgado (1849). Un segundo grupo constituido por una generación más joven nacida entre 1850 y 1863: Justo Blasco (1850), Pedro Urrutia (1850), Emilio Serrano (1850), Tomás Bretón (1850), José Erviti (1852), Antonio Trueba (1855), Melecio Brull (1858),Vicente Mañas (1858), Isaac Albéniz (1860) y Fernández Arbós (1863), entre otros. Por último, hay que señalar la presencia de la pianista Berthe Marx y del violinista Pablo Sarasate, como socios honorarios ${ }^{41}$.

Sin duda, la entidad ofrecía a los músicos un apoyo económico o, en su caso, un modo de subsistencia en un momento en que los músicos veían con pesimismo sus expectativas de trabajo y muchos permanecían en el extranjero ante la falta de oportunidades. Así ocurre con Emilio Serrano, a quien Morphy, preocupado por su porvenir, le otorga el cargo de director del centro, además de profesor de composición, según testimonios ofrecidos por Bretón en su Diario ${ }^{42}$.

Otras personas brindaron su apoyo de manera altruista al Instituto Filarmónico. Destaca la figura de Antonio Romero, quien ofreció el Salón Romero, inaugurado en 1885, para que alumnos y profesores presentasen sus conciertos. También las donaciones realizadas para formar una Biblioteca musical, por parte de Emilio Serrano, el Conde de Morphy, Manuel Giménez, Ramón Rufin, Bonifacio Eslava,Antonio Romero, José Campo, Pablo Martín, Ruperto Cancio, Ramón Campoamor y Domínguez, Cosme J. de Benito, Manuel López Clavo, José Aranguren, La Casa Hug Frères, Casa de Basilea, Casa Ricordi y Casa Milán.

Es significativa la capacidad de Morphy para reunir a 84 distinguidos artistas en una sociedad cooperativa, que respalda su proyecto regeneracionista ${ }^{43}$.

\footnotetext{
${ }^{41}$ Los profesores y socios del Instituto Filarmónico quedan recogidos en la Tabla 1 del Anexo.

42 "Hablamos mucho de su Instituto, que puede encajar ahora menos mal porque Serrano, actual director, alcanzará un pensión de Hacienda y, como esto sea incompatible con Arrieta, resulta un obstáculo de menos, mucho más ofreciendo el Conde dicha dirección a mí o Chapí como garantía para el maestro", T. Bretón, op. cit, p. 399.

${ }^{43}$ Morphy participa del movimiento regeneracionista que antecede al desastre de la guerra hispanoamericana y que tiene entre sus representantes a figuras que, desde ideologías diferentes, denuncian la lamentable situación por la que atraviesa España e intentan aportar medidas de cara a su progreso. Entre sus representantes tenemos a Joaquín Costa, Giner de los Ríos y Menéndez Pelayo, entre otros. Por su parte, Ramón Sobrino destaca la visión "claramente regeneracionista" de Morphy sobre la música española, señalando que "muchas de sus opiniones -que anticipan postulados estéticos en la línea de Pedrell- fueron transmitidas a sus amigos músicos, de ahí que podamos entender la visión que más adelante expone Bretón en sus escritos y epistolario, como una consecuencia del Conde de Morphy", R. Sobrino, op.cit, pp. 61-102.
} 
En sus discursos y escritos ${ }^{44}$, reflexiona sobre la decadencia de España, señalando la necesidad de luchar por el reconocimiento del artista dentro de la sociedad, y de influir en las decisiones del gobierno, a través del "sursum corda de todos los entusiasmos y de todas las voluntades" 45 . Asimismo, denuncia la lamentable situación que vive el arte en España, en comparación a la «regeneración artístico-industrial» de otras naciones europeas ${ }^{46}$. Muestra su preocupación por la decadencia del gusto artístico, junto a la falta de instrucción y educación del público, así como reprocha al gobierno su falta de apoyo a las iniciativas en materia de enseñanza, que buscan alcanzar una España moderna. Por todo ello demanda la unión de todas las fuerzas intelectuales en la lucha del «arte por el arte», sea cual sea su tendencia política, para llevar a España a la "la senda del progreso" 47.

\section{Las tertulias en Los Dos Cisnes y en La Perla}

El Conde de Morphy era un profundo conocedor de las tertulias parisinas entre artistas que tenían lugar en el Restaurant Brebant, a las que asistió durante su exilio en París junto a la reina Isabel II al estallar la Revolución de 1868. En su artículo publicado en Albúm Salón sobre Anton Rubinstein, señala el interés de estas reuniones o "fiestas artísticas" en las que conoció al pianista:

Conocida es la costumbre francesa de reunirse a comer entre hombres solos los compañeros de colegio, los de un mismo pueblo o provincia y los artistas o compañeros ejerciendo la misma profesión. Tal era la comida llamada de los sábados, no por ser cosa de los israelitas, sino porque tenía lugar el primer sábado de cada mes, única noche que tenía libre el director de la ópera, presidente de los comensales. Podían asistir todos los artistas y literatos que quisieran, siendo presentados por un socio y pagando 20 francos. Se celebraba el banquete en el restaurant de Brebant y era tan interesante aquella reunión de celebridades, que, a pesar de mi precaria situación y escasos medios, no dejé de asistir, ni de pagar ningún mes ${ }^{48}$.

Morphy traslada a Madrid su experiencia parisina. Con el propósito de crear "opinión pública" en favor del arte nacional, y estrechar lazos de

\footnotetext{
${ }^{44}$ Morphy deja constancia de los propósitos que marcan su lucha por el arte español en artículos publicados en La Correspondencia de España, Ilustración Española, La Época, La América, El Parlamento, La Gaceta Literaria, Música Ilustrada Hispano-Americana, Álbum Musical, Crónica de la Música, El Año Musical. Además, destaca su colaboración en una de las revistas culturales más prestigiosas del momento, La España Moderna, dirigida por José Lázaro Galdiano donde comparte espacio con Juan Valera, Emilia Pardo Bazán, Emilio Castelar y Marcelino Menéndez Pelayo, entre otros.

${ }^{45}$ G. Morphy: Discurso leído en la apertura de la Sección de Bellas Artes del Ateneo Científico y Literario de Madrid por el sr. conde de Morphy, Madrid, Imp. y Fund. de Manuel Tello, 1886, p. 47.

${ }^{46}$ Ibid., p. 52.

${ }^{47}$ Ibid., p. 49.

${ }^{48}$ G. Morphy: “Antonio Rubinstein”, Álbum Salón, año II, n. ${ }^{\circ}$ 13, 1-III-1898, p. 4.
} 
amistad entre los músicos, a los que veía "faltos de fe y de un ideal que les sirva de guía y de bandera", ${ }^{49}$ organiza reuniones en el restaurante Los Dos Cisnes, situado en la calle Alcalá, 19 y en La Perla, a los que asiste la prensa invitada. Una vez al mes y lideradas por el Conde de Morphy, estas reuniones son secundadas por una generación más joven, que encarna el espíritu reformista de la Restauración. En su primer discurso, Morphy explica los propósitos del Instituto Filarmónico e invita a todos los artistas a unirse a la Sociedad cooperativa, señalando el interés de "que se funde un Círculo o Casino, donde además de estrecharse los lazos de unión entre los socios, haya una verdadera biblioteca musical" ${ }^{50}$. También Emilio Serrano, nombrado director artístico del Instituto Filarmónico, pronuncia el 28 de abril un discurso en el que incide "sobre las excelencias del arte, especialmente de la música, y la conveniencia de la unión de todos los que se consagran al estudio de la misma" 51 . De esta forma, los discursos no se limitaban solamente a dar noticias del centro, sino que eran aprovechados por Morphy y otros socios, como Emilio Serrano o Tomás Bretón, para comentar en tono patriótico el estado de la música en España, en comparación a otros países, y plantear las medidas oportunas para su prosperidad, contando para ello con el apoyo de la prensa:

Si la crítica ha de ejercer alguna influencia en la resolución de problemas, ha de ser la de prensa diaria; el día que por convicción y por patriotismo comprenda que ya es tiempo que los españoles hagamos lo que los demás pueblos han hecho ya hace muchos años, y si a esto se agrega la unión de los músicos para los intereses comunes entonces podrá verse alguna luz en el horizonte obscuro hoy como boca de lobo ${ }^{52}$.

El 5 de enero de 1885 Bretón sorprendió en el banquete celebrado en Los Dos Cisnes ante cuarenta concurrentes, "con la lectura de una interesante Memoria perfectamente escrita y nutrida de curiosos datos y atinadas observaciones". Ante ellos, incidía en el desarrollo "del arte musical en nuestro país, en sus relaciones comparativas con los principales países como Italia, Austria y Francia"53. La Memoria, que había sido escrita durante su estancia en el extranjero como pensionado ${ }^{54}$, había suscitado el rechazo por

49 G. Morphy: "Revista musical”, La Correspondencia de España, año XLVIII, n. ${ }^{14341, ~ 12-V-~}$ 1897, p. 1.

50 "El Instituto Filarmónico", El Liberal, año VI, n. ${ }^{\circ} 1706,15-11 \mathrm{l}-1884$, p. 3.

${ }^{51}$ La Correspondencia de España, año XXXV, n. ${ }^{\circ} 9533,28-I V-1884$, p. 1.

52 G. Morphy: "Revista musical...", p. 1.

53 "El Instituto Filarmónico", La Época, 6-I-1885, n. ${ }^{\circ}$ 11666, año XXXVII, p. 2.

${ }^{54}$ Bretón obtuvo una pensión complementaria gracias a la intercesión de Morphy, con el propósito de completar su formación en Europa y llevar a cabo una memoria sobre los conservatorios extranjeros. V. Sanchez: Tomás Bretón..., p. 91. Desgraciadamente la Memoria escrita por Bretón, que pudo ser fuente de inspiración para algunas de las iniciativas llevadas a cabo en el Instituto Filarmónico, se encuentra en paradero desconocido. 
parte de Arrieta, ya que establecía una comparativa del Conservatorio de Madrid con los conservatorios europeos, con la idea de promover cambios para su modernización ${ }^{55}$. Probablemente, los conocimientos adquiridos por Bretón y los vínculos de amistad que le unían a Morphy, contribuirían a que algunas de sus propuestas se materializaran en el Instituto Filarmónico.

Por su parte, Morphy intenta crear una conciencia propicia para el establecimiento de la ópera nacional, y alienta a los músicos a participar con sus composiciones. Con ocasión del banquete celebrado el 14 de marzo de 1884, Morphy asegura que "con verdadera constancia y trabajo podremos llegar a formar un día la ópera nacional, pues la verdadera inspiración musical de los compositores españoles suministra suficientes elementos para lograr estos deseos" ${ }^{56}$. Un par de meses más tarde, los socios se reúnen para festejar el éxito obtenido por Apolinar Brull con el estreno de su ópera Guldnara, representada en el Teatro Apolo ${ }^{57}$.Y es que entre los mismos socios del Instituto Filarmónico se encuentran los "elementos" aludidos por Morphy, no sólo por contar con dos grandes defensores de la ópera nacional, como eran Bretón y Serrano ${ }^{58}$, sino también por la presencia de Apolinar Brull, Saco delValle, Isaac Albéniz o Gregorio Mateos ${ }^{59}$, interesados en componer música lírica.

Apenas dos años más tarde de la fundación del Instituto Filarmónico, El Imparcial ensalza a su Sociedad al considerarla "como una de las mayores bases de engrandecimiento de la música nacional, a la cual se abrirán nuevos y muchos horizontes, si como es de esperar no encuentran obstáculos sus beneficiosos propósitos" ${ }^{\circ}$.

\footnotetext{
55 "Acerca de la Memoria dice que está equivocada en todas sus partes; que la descripción de los conservatorios era ociosa, pues que ya lo sabían y que él ha visto tantas y cuantas cosas en Viena (como si fuéramos a porfía; y en la última parte me salgo de mi misión, pues no soy legislador sino explorador, como si yo me impusiera; que no encuentra muy feliz la comparación que hago entre España y las demás naciones porque ya sabemos que estamos a tristísima distancia de ellas y, lo seguiremos estando mientras no se diga a todo el mundo", en T. Bretón: Diario..., p. 337 (19-III-1884).

56 "El Instituto Filarmónico", El Liberal, año VI, n. ${ }^{17} 176$, 15-III-1884, p. 2.

${ }^{57}$ La Correspondencia de España, año XXXV, n. ${ }^{\circ} 9585,30-V-1884$, p. 3.

58 "Merece subrayarse la perseverancia y el entusiasmo con que, a diferencia de un Arrieta o un Chapí, por ejemplo se constituyeron en celosos campeones de la ópera española dos compositores cuyos nombres pronuncio siempre con afectuosa gratitud: Emilio Serrano y Tomás Bretón. Ambos nacieron en el año 1850; ambos estuvieron pensionados en la Escuela Española de Bellas Artes de Roma; ambos desempeñaron sendas cátedras de Composición en el Conservatorio de Madrid. Aquel fue durante breve tiempo Comisario Regio del Teatro Real; este asumió durante muchos años la dirección en el citado Conservatorio", en José Subirá: Historia de la Música Española e Hispanoamericana, Barcelona, Salvat, 1953, p. 697.

59 Gregorio Mateos escribió una ópera inédita El alcalde de Zalamea. Según Canora y Molero: Gaceta de Instrucción Pública, n. ${ }^{\circ}$ 1034, año XXII, 15-IX-1910, pp. 386-387.

${ }^{60}$ El Liberal, año VII, n. ${ }^{\circ} 2000$, 6-I-1886, p. 2.
} 


\section{Un proyecto educativo regeneracionista}

El Instituto Filarmónico tuvo una calurosa acogida desde sus inicios en enero de 1884, con la matriculación de unos sesenta alumnos, y la participación de sus cerca de veinte socios fundadores en las labores de enseñanza. El centro fue capaz de ofertar un amplio número de asignaturas en el nivel elemental y superior: piano, violín, violonchelo, contrabajo, arpa, clarinete, oboe, fagot, trompa, cornetín, trombón y canto, además de solfeo, composición, armonía, acompañamiento y transporte al piano del bajo numerado, francés, italiano, declamación lírica, clase popular, literatura musical y canto en español ${ }^{61}$. Asimismo, el centro ofertaba clases de coros de hombres como base de un orfeón ${ }^{62}$.

En un intento por atajar cualquier controversia con el Conservatorio de Madrid, se incide en que "no fueron ideas de rivalidad las que impulsaron a los profesores asociados a fundar el Instituto Filarmónico, y sí otros ideales encaminados noble y principalmente al bien y prosperidad del Arte y de la enseñanza". Además, se agradecen los consejos dados por Morphy en relación a la enseñanza ${ }^{63}$.

Apoyado por su sociedad de 84 artistas, el Instituto Filarmónico ofrecía una educación innovadora, siguiendo modelos europeos ${ }^{64}$. La prensa fue portavoz de sus denotados éxitos, que marcaron desde un principio las diferencias con el Conservatorio de Madrid y que no debieron dejar indiferente a su director Arrieta, acosado por las duras críticas publicadas en prensa. En el Instituto Filarmónico las enseñanzas instrumentales aparecen divididas en dos niveles: elemental y superior ${ }^{65}$. Así, se atendía, por un lado, a los alumnos aficionados que se dedicaban "a la música por recreo" y, por otro, a los que buscaban abrirse camino en el difícil panorama de la época, bien como intérpretes en orquestas, compositores o cantantes con destino a los teatros líricos. De forma similar, los estudios de armonía se dividían

${ }^{61}$ El 25 de noviembre de 1885 se aprueba la validez académica de los centros de libre enseñanza de caracter privado, mediante reválidas o pruebas de aptitud reguladas por el gobierno, Gaceta de Madrid, n. ${ }^{\circ} 327,25-X I-1885$, p. 575.

${ }^{62}$ La Época, año XXXVI, n. ${ }^{\circ} 11415,24-I V-1884$, p. 3.

${ }_{63}$ Memoria 1884-1885, p. 8.

${ }^{64}$ Morphy conocía la realidad de otros conservatorios europeos. Hay que señalar que en 1863 estuvo encargado de redactar una Memoria sobre los Conservatorios líricos y Sociedades corales europeas "a cuyo fin viajó por casi toda Europa", en Manuel Ovilo y Otero: "El caballero Morphy", Escenas Contemporáneas, tomo II-III, 1883, p. 337. Además conocía la Memoria realizada por Bretón sobre el funcionamiento de estos centros. En la España moderna Morphy hace referencia a los conservatorios de Bruselas, Berlín y Viena, de los que afirma que "la enseñanza musical ha llegado al mayor grado de perfección", y que deben servir de modelo al Conservatorio de España, G. Morphy: "Revista musical", La España Moderna, año VI, n. ${ }^{\circ}$ LXXI, octubre de 1894, pp. 155-162.

${ }^{65}$ Las asignaturas aparecen divididas en primer y segundo grado y además se ofrece "Tercer grado o perfeccionamiento en cualquier enseñanza", Salón-Romero. Almanaque musical, Madrid, Ediciones Romero, 1885, p. 55. 
en dos ramas, según estuvieran dirigidos a "profesores leccionistas" o a compositores $^{66}$.

Respecto a la cátedra de Canto, se le confiere una atención especial acorde a los propósitos de Morphy de establecer la ópera nacional. De manera similar al Conservatorio de Madrid, se imparten las asignaturas de Canto, Conjunto vocal y Declamación. Sin embargo, el Instituto crea nuevas asignaturas de clases populares y clases de canto en español, atendiendo al repertorio lírico español. Además, se incluye la asignatura de Literatura Musical, que completa la formación de los alumnos dedicados a dar vida a las creaciones dramáticas de todas las épocas ${ }^{67}$.

Por otra parte, se establece un número máximo de alumnos por aula, como "único medio de que la enseñanza produzca verdaderos resultados artísticos, y el único también de que los alumnos lo sean exclusivamente del profesorado de este Centro" 68 . De este modo, parece aludir a los problemas de masificación del Conservatorio y a la demanda de las enseñanzas privadas por parte de sus alumnos ${ }^{69}$. El Instituto atendía a un máximo de veinte alumnos en las clases de Solfeo, 8/12 alumnos en el primer grado de las asignaturas instrumentales y la mitad, 4/6 en el segundo grado ${ }^{70}$.

Respecto a los exámenes, se establecía una periocidad trimestral, y al contrario de lo que sucedía en el Conservatorio, eran de carácter público y ante tribunal. Además el centro impartía Conjunto Instrumental y, a diferencia del Conservatorio, cuyas clases finalizaban en mayo, ofrecía enseñanzas hasta finales de junio ${ }^{71}$. Todas estas medidas convirtieron al Instituto Filarmónico en un centro único en España, a la altura de otros centros extranjeros, tal y como podemos leer en El Magisterio español:

Es verdaderamente merecedora de los mayores elogios la decisión y entusiasmo de los señores Profesores asociados, que bajo la inteligente dirección del Conde de Morphy establecieron el Instituto filarmónico, por el arte y para el arte. Dicho centro, instalado con cuidadoso esmero y elevado a gran altura en los tres años que lleva de existencia por el celo y la ilustración de su personal docente, es el único de su clase en España, y nada tiene que envidiar a las escuelas o conservatorios del extranjero que mayor renombre han alcanzado ${ }^{72}$.

${ }^{66}$ Para los primeros se dirigen los estudios prácticos de acompañamiento y transposición de bajos numerados. Véase Instituto Filarmónico de Madrid. 1886, Madrid, Impr. de José M. Ducazcal, 1886, p. 4.

67 Véase Cuadro 2 del Anexo.

68 Ibid, p. 4.

${ }^{69}$ A causa de las aulas masificadas, muchos alumnos recurrían a profesores particulares. En las clases de solfeo, quinientos alumnos eran atendidos por tres profesores de número, más seis auxiliares que ayudaban en la enseñanza. Aún peor eran las clases de piano superior, con cerca de ochocientos alumnos para tres profesores de número y siete auxiliares, correspondiendo ochenta alumnos para cada profesor, según Toboada, op.cit, p. 9.

70 Según datos publicados en Salón-Romero. Almanaque Musical..., p. 55.

${ }^{71}$ Véase Cuadro 3 del Anexo.

72 El Magisterio Español, año XX, n. ${ }^{\circ}$ 1276, 30-VIII-1886, p. 2. 
Gracias al prestigio alcanzado, el Instituto Filarmónico se convirtió en un centro de referencia para otras instituciones educativas. Así, su modelo de enseñanza fue adoptado por otro Instituto en Matanzas (Cuba), inaugurado en 1886 por el profesor Francisco Cortadellas, según consta en una de las Memorias del centro ${ }^{73}$. Además, uno de sus profesores, el pianista y compositor Vicente Mañas, parece haberse inspirado en algunas de las propuestas del Instituto Filarmónico a la hora de fundar el Conservatorio de Música y Declamación de Alicante en $1889^{74}$, del que era presidente honorario Emilio Arrieta ${ }^{75}$, y establecer, en 1895, el Conservatorio Provincial de Música de Matanzas "al estilo del Instituto Filarmónico de Morphy"76.

Durante el curso 1885-86, la entidad obtiene el reconocimiento por parte del ministro de Fomento, Eugenio Montero de los Ríos, quien le otorga una subvención de 2000 pesetas. Así ganaba "un nuevo y valioso amigo" con la presencia del delegado de Fomento Francisco Carsi y Osorio, en las juntas y actividades del centro, y lo que era más importante, un posible "protector de los ideales del centro" "77.

\section{Las clases de canto y su significado en la controversia de la ópera nacional}

Gran defensor de la ópera nacional, Morphy intentará ayudar a Tomás Bretón en el estreno de su ópera Los amantes de Teruel durante estos años ${ }^{78}$. El Instituto Filarmónico se ofrecía como el medio ideal para formar artistas con destino a los teatros líricos. Con este fin, su escuela de canto contaba, para impartir las asignaturas de Declamación lírica y Clase popular, con destacadas personalidades relacionadas con el Teatro Real, como eran Francisco Saper (director artístico del Teatro Real), Antonio Oller y Biosca

\footnotetext{
${ }^{73}$ Memoria presentada por la junta directiva, 1885-1886..., pp. 4-5. Francisco Cortadellas, socio del Liceo de Matanzas, cuyas artes recibieron un gran impulso de 1882 a 1886, se había asesorado por la directiva del Instituto Filarmónico de Madrid para fundar su Instituto en Matanzas, nombrando presidente honorario a Apolinar Brull.

${ }^{74}$ Información obtenida en Fernando Carrasco Vázquez: Vicente Mañas Orihuel. Aproximaciones a su vida y obra, tesis de maestría, Universidad Autónoma de México, 2010.

${ }^{75}$ La Correspondencia de España, año XL, n. ${ }^{\circ} 11443$, 1-VIII-1889, p. 1.

76 Vicente Mañas, op. cit., p. 41.

77 Memoria presentada por la junta directiva 1885-1886, Madrid, Impr. José M. Ducazcal, 1886, p. 7.

${ }^{78}$ El 28 de abril de 1885 comienza una agria polémica por el estreno de la ópera de Tomás Bretón para ser representada en el Teatro Real, en base a la clausura $6 .{ }^{a}$ del contrato de arrendamiento, que dictaminaba la obligación de poner en escena una obra de autor español. La controversia con Arrieta y las dificultades económicas por las que pasaba su empresario Michelena resultaron un calvario para Tomás Bretón y para el mismo conde de Morphy, que le ayudaba en su propósito, según queda reflejado en el Diario de Bretón.
} 
(maestro al piano y organista del Teatro Real) y Gregorio Mateos ${ }^{79}$ (organista y maestro concertador del Teatro Real). Además de una figura de gran peso en la escena lírica, NapoleónVerger, quien compartía la clase de canto con Antonio Trueba y Justo Blasco ${ }^{80}$. No menos significativa era la presencia, como socio fundador del Instituto, del Conde de Michelena, empresario del Teatro Real, y figura clave para el establecimiento de la ópera nacional ${ }^{81}$.

El Instituto Filarmónico respondía a las inquietudes nacionalistas al incluir las Clases populares, y las clases de canto en español. La Memoria de ese año justifica la decisión, en medio de la controversia de la ópera nacional:

Si bien es cierto que la enseñanza del Canto en idioma italiano es importante, por ser el que domina en primer término en el mundo musical, no lo es menos que, aun cuando no fuere más que por patriotismo, debemos tener en nuestro Instituto una Clase de canto en español, y con mayor razón, en estos tiempos, que es tema de controversia la creación y planteamiento de la ópera nacional ${ }^{82}$.

79 Gregorio Mateos (Madrid, 1858- 1910) fue alumno de Compta y Pinilla en el Conservatorio. En 1876 y 1877 segundo y primer premio, respectivamente, de armonía y composición. Ocupó el puesto de profesor en el Colegio Nacional de Sordomudos durante nueve años, destacándose en los conciertos en los que dirigió a las masas corales. Estudió canto con Martín Salazar, Juan Goula y Napoleón Verger. Fue profesor auxiliar de órgano en el Conservatorio en 1882. Durante 26 temporadas desempeñó indistintamente en el Regio Coliseo los cargos de pianista, organista y maestro concertador. Siendo repasador de cuantos artistas eminentes han pisado las tablas de nuestro primer teatro lírico. Fue individuo del Jurado para la admisión de óperas españolas, Canora y Molero, op. cit, pp. 386-387.

80 Justo Blasco (1850-1911) es autor de la obra Escuela práctica para la emisión de la voz publicada por Antonio Romero durante los años que ejerció como profesor en el Instituto Filarmónico. Desde 1890 es nombrado profesor interino del Conservatorio a propuesta del claustro de profesores y dos años más tarde ocupa la Cátedra de Canto en el mismo establecimiento. Véase Mariano Pérez Gutiérrez: "Blasco Compans, Justo", Diccionario de la Música Española e Hispanoamericana, Emilio Casares Rodicio (dir.), Madrid, SGAE, 1999, vol. II, pp. 527-528.

${ }^{81}$ Desde que comienza la polémica por el estreno de Los amantes de Teruel en 1885, fueron numerosos los contactos de Morphy con el Conde de Michelena, para lograr la representación de la ópera de Bretón en el Teatro Real, tal como se refleja en el Diario de Tomás Bretón. En este contexto, su elección como socio fundador del Instituto Filarmónico, respondería al deseo de Morphy de estrechar los vínculos entre Michelena y los artistas, implicándolo en el objetivo anunciado por el Instituto Filarmónico de luchar por el arte lírico nacional, apoyando el establecimiento de la ópera nacional. Michelena no solo contribuyó al sostenimiento económico del centro, sino que también facilitó el acceso de sus alumnos de canto al Teatro Real. Pese a todo, fueron años de lucha hasta la firma del acuerdo para el estreno de la ópera de Bretón, el 23 de marzo de 1888, que, finalmente se representaría el 12 de febrero de 1889. Entre las razones que pesaron en el ánimo de Michelena para retrasar dicho estreno estarían la influencia de Arrieta, que "llena la cabeza de miedo a Michelena diciéndole que la obra es muy mala y que su estreno va a ser un escándalo", Diario..., p. 487, sumado a la deuda contraída por la empresa con el Estado por el impago de arriendo del Teatro Real, que le llevará a su cese por suspensión de pagos, en 1894, Joaquín Turina: Historia del Teatro Real, Madrid, Alianza Editorial, 1997. De sumo interés para la época que nos ocupa es la publicación de José María Domínguez basada en documentos, en su mayoría inéditos, procedentes del archivo personal del Conde de Michelena, donde muestra las tensiones a las que se enfrentó durante su gestión al frente del Teatro Real. El autor destaca la capacidad de Michelena para encontrar "un equilibrio entre su propio interés económico, la razón comercial y la calidad artística", J. M. Domínguez: "El Teatro Real de Madrid durante la gestión del empresario Ramón de Michelena (1882-1894)”, Acta Musicológica, LXXXVII, 2, 2015, pp. 217-232.

82 Ibid., p. 5. 
De este modo, el plan de enseñanzas del centro refleja el ideario regeneracionista de la ópera española proclamado por Morphy, y compartido por Emilio Serrano y Tomás Bretón ${ }^{83}$, quienes defendían una ópera escrita en castellano, distanciándose de los argumentos regeneracionistas de Barbieri y Arrieta ${ }^{84}$. Parece clara la implicación de Tomás Bretón en las enseñanzas del Instituto Filarmónico, para quien era una prioridad "españolizar las enseñanzas, tanto en los libros de texto como en las clases de canto, argumentando las amplias posibilidades del castellano como idioma musical, en una propuesta dirigida directamente contra Emilio Arrieta". Asimismo, Bretón, en su escrito Más en favor de la Ópera Nacional, defendía la formación de una compañía estable de ópera formada por cantantes españoles que cantaran no solo las obras de autores nacionales, sino también del repertorio extranjero traducido al español.

\section{La escuela de canto del Instituto Filarmónico: Napoleón Verger y los conciertos}

En 1883 Napoleón Verger ${ }^{85}$, una figura de primer orden que había cosechado innumerables éxitos en los escenarios líricos de Europa y América, acepta la proposición del Conde de Morphy para impartir clases de canto en el Instituto Filarmónico. Si bien durante estos años es víctima de una grave dolencia, que le aparta de los grandes teatros, continúa ofreciendo conciertos en España, que le valen la encomienda de Isabel la Católica en $1886^{86}$. Su ardua labor creó una auténtica escuela de canto en Madrid, respondiendo a las necesidades del repertorio italiano, para el que "los artistas tenían que hacer grandes estudios de agilidad que no se adquirían sino

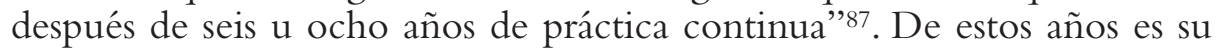

\footnotetext{
83 Véase V. Sanchez: Tomás Bretón..., p. 139.

84 Véase Emilio Serrano y Ruiz: "Estado actual de La música en el Teatro", Discursos leídos ante la Real Academia de Bellas Artes de San Fernando en la recepción pública del Ilustrísimo Señor D. Emilio Serrano y Ruiz, 3 de noviembre de 1901, Impr. de la Revista de Legislación, Madrid, 1901, p. 22; T. Bretón: Más en favor de la ópera nacional, p. 28. Referido en V. Sanchez: Tomás Bretón..., p. 137; "Barbieri. La ópera nacional", Discursos leídos ante la Real Academia de Bellas Artes de San Fernando en la recepción pública del Ilustrísimo Sr. D. Tomás Breton, 14 de mayo de 1896, Madrid, Imp. hijos de José M. Ducazcal, 1896.

${ }^{85}$ Napoleón Verger (Palermo, 1844-1907) era hijo del destacado tenor italiano Juan Bautista Verger y hermano de Amadeo Verger, empresario del Teatro italiano de París. En 1862 llega a París para estudiar con Porto, dando su primer concierto en 1863, en la casa Herz y dos años más tarde debuta en el Teatro italiano con la ópera Ernani. Allí será contratado durante seis años, cosechando innumerables éxitos y a la altura de los grandes como Penco, Kraus, Mario, Graciani o Gardoni. También se hizo muy popular por sus dotes musicales como barítono, en América. En España canta durante largas temporadas en el Real (La Ilustración, 23-XI-1884, año IV-V, n. ${ }^{\circ} 212$, p. 6). El 21 de noviembre de 1887 es nombrado Profesor de Cámara por la Reina regente en nombre de su hijo Alfonso XIII (La España, 21-XI1887, año II, n. ${ }^{\circ} 47$, p. 749). En noviembre de 1888 es contratado en Barcelona para colaborar en seis conciertos extraordinarios por la compañía que actúa en el Circo (La España Artística, año I, n. ${ }^{\circ}$ 20, 1 XI-1888, p. 3).

${ }^{86}$ La Época, año XXXVIII, n. ${ }^{\circ} 12047,2-I I-1886$, p. 4.

${ }^{87}$ Ramiro Alta-Villa: Método completo de canto, Madrid, Sucesores de Hernando, 1906, p. 447.
} 
obra 12 ejercicios para el estudio del canto, escrita en colaboración con Antonio Trueba ${ }^{88}$. Entre sus alumnas de canto se cuentan: Bibiana Pérez, Aldao, Oliva, Amalia Pauli, Ana López Peñafiel ${ }^{89}$, Moreno Leante, Amparo Romaguera, Matilde de Lerma ${ }^{90}$, Ramona González de Molada, Concepción Egido, Salud Merchán, Ramona Umbert, Enriqueta Aceña, María Galvany y López Moran. ${ }^{91}$ Y los alumnos: Cardona, Artigana, Ignacio Varela, Villamar, Lillio, Ignacio Tabuyo, Antonio Astigarraga, Rafael Bezares, Francisco Granados y Luis Iribarne ${ }^{92}$.

Los conciertos del Instituto Filarmónico se celebraban en el Salón Romero, un magnífico establecimiento fundado en la calle de Capellanes, destinado de manera altruista por su fundador Antonio Romero y Andía, a impulsar el arte nacional. Los conciertos se programaban al menos dos veces por año, en febrero y junio, coincidiendo con los exámenes. En ellos, los alumnos de Verger solían ser los protagonistas, ofreciendo un amplio repertorio de obras de Bellini, Donizetti,Verdi, Rossini, Mozart, Meyerbeer, Gounod, Cimarosa y Corti. Merece mención especial el concierto de inauguración, del 29 de diciembre de 1884, organizado por el Instituto, que fue todo un acontecimiento. Al mismo asistieron "SS.MM. y AA.RR., ocupado el Salón con sus anchurosos pasillos de un numerosísimo público, contando entre él cuanto de notable se dedica en Madrid al cultivo de las bellas artes" 93 . El Conde de Morphy daba a conocer algunas de sus composiciones como A prima para coro, y su romance para voz y coro La despedida del Cid. Además, los profesores del Instituto hacían su presentación ante el público, interpretando una Suite de Bach y la Sinfonía en Si b M de Haydn, dirigida por Bretón. En el concierto "que duró tres horas y media, no cesaron de aplaudir y celebrar la buena ejecución y el mérito de las obras escogidas" 94 .

\footnotetext{
88 Se ha podido localizar esta obra en la Biblioteca Musical Víctor Espinós en Madrid, sig. M-BMM BMDE Depósito C 201003599761.078

${ }^{89}$ Por mediación de Verger, Peñafiel fue invitada en Palacio para dar un recital en honor al príncipe Jorge de Inglaterra. Concierto que, finalmente, no pudo llevarse a cabo. En junio de 1888, obtiene sonado éxito y "asombró a su auditorio" en el concierto del Instituto Filarmónico, obteniendo por la Junta directiva y el Claustro de profesores diploma de honor y pasando a ser socia de mérito del mismo. Véase "Srta. Doña Ana Lopez Peñafiel", Cartagena Artística, año 1, n. o 16, 10-IX-1890, p. 1.

${ }_{90}$ Matilde de Lerma logró un gran éxito el día de su debut en el Teatro Príncipe Alfonso, con la ópera Mefistófeles, en La Correspondencia de España, año XLVIII, n. ${ }^{\circ}$ 14325, 26-IV-1897, p. 3.

${ }^{91}$ Información tomada de Carmen Ramírez: Luis Iribarne (1868-1928). Un cantante en la escena lírica universal, Instituto de estudios almerienses, 2010, pp. 49-50; y de F. Cuenca: Teatro andaluz contemporáneo, vol. II, p. 45.

92 Francisco Granados era una de las glorias nacionales. De excelente nivel artístico componía la escuela española de tenores continuadores de la estela de Julián Gayarre. Por su parte, Luis Iribarne (18681928) llegó a Madrid en 1888 y allí estudió canto con Napoleon Verger, "vieja Gloria siciliana del Real, retirado de la escena por motivos de salud, ejercía el magisterio del canto en el corazón de Madrid, calle de las Hileras 17", Guía comercial de Madrid, Madrid 1889, Madrid, Bailly-Baillière e hijos, p. 316.

${ }^{93}$ Memoria Instituto Filarmónico. 1884-1885, Madrid, Impr. de José Ducazcal, 1885, pp. 3-4

94 "El Instituto Filarmónico", La Época, n. ${ }^{1} 1661,1-I-1885$, p. 4.
} 
Entre otras actuaciones, la crítica hacía grandes elogios del repertorio lírico, interpretado por parte de Verger y de algunos de sus alumnos "que a juzgar por la perfección con que ejecutaron las obras que les estaban encomendadas, más que discípulos, parecían verdaderos artistas"95.

Pero los alumnos de Verger no sólo actuarían en el Salón Romero, sino que llevaron a cabo una intensa actividad concertística en otros escenarios $^{96}$. Con ocasión del concierto benéfico organizado en el Real, El Liberal destaca las dotes artísticas de Oliva, "una de las alumnas más aventajadas del sr.Verger, que ya en algunos conciertos del Teatro Real cantó al lado de la señorita Teodorini con gran éxito. Ha obtenido en los teatros de Italia muchos triunfos cantando el repertorio de Donizetti,Verdi y Gounod"97. También, el 27 de junio de 1887, destacan Paoli y Herrero al estrenar las Canciones sobre poemas de Bécquer de Tomás Bretón ${ }^{98}$. La España señala: "por mucho que esperábamos de los grandes méritos de tan distinguido profesor [se refiere a Verger] y de las indisputables dotes de sus discípulos, nunca hubiéramos podido sospechar que estos llegaran al punto que han alcanzado en el difícil arte que cultivan" $" 99$. Dos años más tarde, el 3 de mayo de 1888, las Canciones de Bretón vuelven a interpretarse, en el Teatro del Príncipe Alfonso, con motivo de las catástrofes ocasionadas por la inundaciones de León, destacando, en esta ocasión, la interpretación de Las golondrinas de Tomás Bretón, por parte de Bibiana Pérez ${ }^{100}$. Por último, son reseñables las actuaciones llevadas a cabo con la Sociedad de Conciertos dirigida por Tomás Bretón, por parte deVerger y algunos de sus alumnos más destacados, durante las temporadas de verano del Casino de San Sebastián ${ }^{101}$ y, asimismo, en los conciertos ofrecidos en el Ateneo con motivo de las conferencias impartidas por el Conde de Morphy ${ }^{102}$.

Sin embargo, el acontecimiento más importante tuvo lugar el 12 de febrero de 1889, con el éxito del estreno en Madrid de la ópera de Bretón Los amantes de Teruel, tras cuatro años de intensa lucha por llevarla a los escenarios. Para Morphy -según él mismo escribe en El Imparcial- la ópera de Tomás Bretón constituía "el punto de partida decisivo en la historia del drama lírico nacional" "103. Turina señala cómo "el triunfo de Bretón se usa

\footnotetext{
${ }^{95}$ Memoria $1884-1885 \ldots$, p. 4.

96 Cuadro 4 del Anexo.

${ }^{97}$ El Liberal, año VIII, n. ${ }^{\circ} 2567$, 16-VI-1886, p. 3.

98 V. Sánchez: Tomás Bretón..., p. 177.

99 "El Instituto Filarmónico", La España, año II, n. ' 28, 28-VI-1887, pp. 444-445.

100 V. Sánchez: Tomás Bretón..., p. 178.

${ }^{101}$ Ilustración Musical, año III, n. ${ }^{\circ}$ 65, 30-IX-1890.

102 Los conciertos en el Ateneo tuvieron lugar el 23-XII-1886, el 16-III-1887 y el 25-II-1894. La Correspondencia de España, año XXXVIII, n. ${ }^{\circ} 10585$, 16-III-1887, p. 2.

103 G. Morphy: "Los amantes de Teruel", El Imparcial, 3-II-1889. Referido en V. Sánchez: Tomás Bretón..., p. 155.
} 
como una bandera por las nuevas generaciones contra los “viejos" Barbieri y Arrieta, a los que se reprocha su posición poco clara en los informes y dictámenes que se remitieron de esta ópera"104. En el estreno de la obra, participaba Bibiana Pérez en el papel principal de Isabel Segura, además de Vicente Mejía, otro alumno destacado de Verger ${ }^{105}$. La prensa destaca el gran esfuerzo de los cantantes y su sólida formación, y en particular menciona la maestría de Bibiana Pérez y sus progresos artísticos ${ }^{106}$. Ambos cantantes formaron parte de la Compañía de ópera dirigida por Pedro de Urrutia, debutando en el Teatro de Calderon de Valladolid, con Los amantes de Teruel dirigida por el propio Bretón ${ }^{107}$ " $\mathrm{y}$ en las noches siguientes con Lucia, Favorita, Traviata, y Hugonotes" 108 . Posteriormente, continúan actuando en Salamanca, donde "tanto el eminente Bretón, como la Srta. Bibiana Pérez y principales artistas, recibieron entusiastas ovaciones, siendo aquellos obsequiados con multitud de coronas" 109 . Gracias a los éxitos obtenidos, Alfredo Volpini contrata a la compañía para que actúe en el gran Teatro Tacón de La Habana ${ }^{110}$.

Por su parte, Ignacio Tabuyo participa en varias temporadas en el Real, tomando parte en el estreno de Giovanna la Pazza, Irene de Otranto y Doña Juana la Loca de Emilio Serrano ${ }^{111}$ y Rachel de Antonio Santamariía; otra alumna de Verger, Matilde de Lerma, actúa en el estreno de

${ }^{104} \mathrm{~J}$. Turina, op. cit, p. 160.

105 Se hicieron siete representaciones con 23 ensayos en el Real. Ibid., p. 160.

106 "Los cantantes encargados de ejecutarla han tenido que practicar prolongados estudios, asistiendo después asiduamente al gran número de ensayos que ha exigido la obra. Pero han sabido vencer todas las dificultades y dominar con absoluto imperio la ardua tarea que les fue encomendada. No hubo vacilaciones de ningún género y todos los interpretes de la ópera estuvieron, dadas sus condiciones, en plena posesión de sus respectivos papeles. Bibiana Pérez cuyos progresos en el arte de día en día son más notorios, cantó la parte de Isabel Segura con verdadera maestría, imprimiendo siempre delicadísimo sentimiento a la frase y representando con sumo acierto el poético tipo de la infortunada amante Marsilla". En: "Los amantes de Teruel", El Liberal, Madrid, 13-II-1890. Referido en V. Sanchez, op. cit., p. 153.

107 "En dicho cuarteto figuran artistas de gran mérito, como la tiple Doña Bibiana Perez y los señores Valero y Mejía, a más le acompañan los magníficos coros del citado coliseo, un gran número de profesores de su aplaudida orquesta; todos bajo la dirección del maestro Urrutia”. La Ilustración Musical, año II, n. ${ }^{\circ} 31,23-I V-1889$, p. 64.

108 "Se destaca del cuadro, sin pero alguno, como refulgente estrella del arte, la angelical diva Srta. [Bibiana] Pérez. Su sola aparición puesta en nuestra escena ha bastado para conquistarla todas las simpatías y cuando su privilegiada garganta derrama profusamente mil perlas armónicas, el entusiasmo del público raya en delirio". En: Adolfo J. de Gumucio: La España artística, año II, n. ${ }^{\circ} 46,15-V-1889$, p. 3.

${ }^{109}$ La España artística, año II, n. ${ }^{\circ} 49,8-V I-1889$, p. 3.

110 «Compañía lírica, compuesta exclusivamente de artistas españoles de los que más han sobresalido en la ópera italiana, tales como la señora Volpini, la Paoli, la Pérez, Marín, Viñas, Valero, Blanchard y otros que actualmente son aplaudidos en los principales teatros de Italia. Esta misma compañía cantará las óperas en italiano y en español, dándonos a conocer la del maestro Bretón, titulada Los amantes de Teruel", La España artística, año II, n. ${ }^{\circ} 49,8-V I-1889$, p. 3.

111 Obras Orfeo de Gluck, Tanhauser de Wagner, Doña Juana la Loca de Emilio Serrano y Los amantes de Teruel de Bretón. En: Ilustración Musical, n. ${ }^{\circ} 41$, 22-IX-1889, p. 144. 
Raquel de Bretón ${ }^{112}$; Astigarraga ${ }^{113}$ lo hará con La Dolores también de Bretón, en Buenos Aires y, por último, Araceli Aponte y Amalia Paoli en el Teatro Real ${ }^{114}$.

En 1889 Michelena publica un documento en el que, guiado por «el móvil patriótico» se compromete con la creación de una Academia Coral dentro del Teatro Real, formada en su totalidad con elementos españoles. Además, recuerda el compromiso constante de la empresa en "dar ingreso en sus cuadros de compañía al mayor número de artistas españoles”, logrando "repetidas veces llenar este deseo, respecto a muchas primeras partes, que como tales actúan en el espectáculo, toda vez que, por fortuna, cuenta hoy España con una pléyade brillante de artistas, que recorren con gloria y aplauso los primeros teatros líricos de Europa y América" ${ }^{115}$.

\section{Epílogo}

El Instituto Filarmónico finaliza su último curso en 1888-89 “con el brillante resultado que era de esperar del buen nombre de los señores profesores encargados de la enseñanza" 116 . Tras los triunfos obtenidos por Bretón, el Instituto había logrado su propósito más importante, contribuir al impulso del arte lírico español. A partir de septiembre de 1889, Napoleón Verger seguirá formando artistas desde su propia academia en la calle de las Hileras, continuando de este modo el proyecto iniciado por Morphy. Respecto al resto de profesores, irán ocupando otros puestos que les procuran mayores beneficios y seguridad. Por un lado, algunos de ellos, que pertenecían a la Sociedad de Conciertos, fueron llamados para actuar en las numerosas representaciones de ópera. Asimismo, Tomás Bretón, tras los éxitos de su estreno, se vuelca en nuevos compromisos, con la dirección de la orquesta y compañías de ópera y en la composición de nuevas obras. Por otro lado, muchos profesores fueron incorporándose paulatinamente al

112 V. Sánchez, op. cit, p. 313

113 Astigarraga nació en Gipúzcoa (Eibar), trasladándose en 1882 a México, donde sorprendió por sus dotes como cantante, posteriormente, viajó a Madrid y, a través de Plácido Zuloaga, amigo del Conde de Morphy, es presentado a este, quien a su vez le lleva ante el rey Alfonso XII acompañado del maestro Emilio Serrano. Entusiasmó tanto al rey con sus cantos, que le pensionó para que tras estudiar en Madrid, viajara a Milán. Debutó en La Scala, en Venecia, y más tarde en América. www.diariovasco.com/ bajo-deba/asti-tenor (última consulta 14-1-2016).

114 Véanse algunos de los conciertos en el Teatro Real en el Cuadro 5 del Anexo.

115 Reglamento para la organización y régimen de la Academia Coral de ambos sexos establecida en el Teatro Real de Madrid, Madrid, Imprenta de José M. Ducazcal, 1889, p. 7. Según señala José María Domínguez, op. cit., p. 225, el documento se publicó "quizá con la intención de responder a la larga polémica mantenida por Bretón durante la etapa anterior y de conciliar el éxito que este obtuvo con Los amantes deTeruel en febrero de 1889".

${ }^{116}$ El Imparcial, año XXIII, n. ${ }^{\circ} 7951,8$-VII-1899, p. 2. No se han encontrado otras noticias posteriores sobre la actividad del centro. 
Conservatorio ${ }^{117}$, desde donde se fueron realizando algunos cambios bajo la dirección de Arrieta, como incorporar la asignatura de Gramática Castellana y Preceptiva Literaria para los cantantes, o la de Conjunto instrumental. Cambios que reciben el aplauso de Morphy, quien, con motivo del concierto celebrado en el centenario de la muerte de Mozart, alaba los progresos de la enseñanza y ensalza la labor de su director, Arrieta, de los profesores y alumnos ${ }^{118}$.

\section{Conclusiones}

A la vista de los resultados, el Instituto Filarmónico es una aportación relevante al asociacionismo musical en el periodo de la Restauración, en el aspecto de la instrucción y de la sociabilidad. Impulsado por el Conde de Morphy, es un ejemplo de cómo las iniciativas privadas tratan de mejorar la situación musical a través de propuestas de progreso hacia lo que consideran una España moderna. Su proyecto pedagógico de carácter regeneracionista pone en evidencia las carencias de la enseñanza musical del Conservatorio de Madrid, percibido como un centro anquilosado, con un reglamento obsoleto. El Instituto Filarmónico busca el beneficio de la sociedad al extender la educación a todas las capas populares y, al mismo tiempo, ofrece una sólida formación a los futuros profesionales de la música, muchos de ellos procedentes del Conservatorio de Madrid.

117 En 1888 se incorporaron al Conservatorio Melecio Brull (auxiliar en 1888 y numerario en 1889), Enrique F. Arbós (violín), Francisco González Maestre (flauta), José Valderrama (trombón), Fermín Ruiz (oboe). En los años siguientes: Valentín Arín (armonía) y Justo Blasco (canto) en 1890, Salvador S. Bustamante (piano), como auxiliar en 1892, numerario en 1896 y Vicenta Tormo (arpa) en 1904. Datos obtenidos de Federico Sopeña: Historia crítica del Conservatorio de Madrid, Madrid, Ministerio de Educación y Ciencia, 1967. Otros son requeridos en otro tipo de puestos, como es el caso de Apolinar Brull que pasa a ser maestro-concertador de la compañía cómico lírica, en 1889; Pedro de Urrutia como director de compañías de ópera (El Fomento, año IX, n. ${ }^{\circ}$ 1538, 29-V-1889, p. 3); Cruz Cerezo y Albar, alumno de Zabalza, se estableció en América en 1886, llevando a cabo una intensa actividad como concertista y profesor (El País, año XVI, n. ${ }^{\circ}$ 5619, 22-XII-1902, p. 3).

118 "La fiesta resultó brillante y, considerada en conjunto, revela gran progreso en la enseñanza de aquel centro oficial. Justo es ante todo, dar gracias a su ilustre director, que, al organizar este concierto, ha considerado con razón la gloria y la figura de Mozart como universales, y en tal sentido leyó un breve y sentido discurso que ya conocen en parte los lectores de este periódico. No encuentro elogios bastantes para ensalzar la conducta del sr. Arrieta, de los profesores y de los alumnos del Conservatorio, pues todos pusieron de su parte cuanto pudieron para reunir tributo a la memoria del Rafael de la música", G. Morphy: "El centenario de Mozart en el Conservatorio", La Correspondencia de España, año XLII, n. ${ }^{\circ}$ 12317, 27-XII-1891, p. 1. Otras medidas contempladas en el Instituto, como el límite de alumnos por clase, el establecimiento de los exámenes públicos o la introducción del repertorio lírico español en las clases de canto, fueron aplicadas a partir de 1900 por Tomás Bretón como director. Datos obtenidos en Memoria precedida del discurso de Tomás Bretón. 1900-1901, Madrid, M. Ducazcal, 1901, p. 6; y Memoria precedida del discurso de Tomás Bretón. Curso 1901-1902, Madrid, Impr. Colonial, 1902, p. 9. 
Sus resultados son sometidos al juicio del público y de la prensa, con la organización de conciertos en los que participan alumnos y profesores, que así contribuyen a dinamizar el movimiento musical en Madrid.

Además, su escuela de canto se compromete con el planteamiento nacionalista de una ópera cantada en español, siendo una de las primeras en la impartición del canto en este idioma. Prepara el camino al drama lírico nacional con la formación de notables artistas y contribuye al éxito de las óperas de Tomás Bretón y Emilio Serrano, entre otras. Queda patente que la entidad sirvió de referente a otros centros instructivos dentro y fuera de España y probablemente sus logros incidieron en el gobierno a la hora de nombrar a Morphy miembro de la comisión encargada de las reformas en el Conservatorio de Madrid.

Por último, esta investigación se acerca a un personaje relevante de la música española caído en el olvido, el Conde de Morphy. Revela su preocupación por la enseñanza y el esfuerzo que hizo para unir al mayor número de artistas en torno a su proyecto del Instituto Filarmónico, bajo el ideal "por el arte y para el arte" y también a favor del establecimiento de la ópera nacional. Las tertulias en Los Dos Cisnes y La Perla se presentan como espacios de sociabilidad en los que se estrechan lazos entre artistas, convirtiéndose en un foro de encuentro, información y debate sobre el futuro del arte nacional, bajo la guía intelectual de Morphy. Sus premisas para impulsar una renovación musical en España y su influencia sobre los jóvenes artistas de su tiempo serán objeto de futuras investigaciones. 
Cuadro 1. Socios y profesores del instituto Filarmónico

\begin{tabular}{|c|c|}
\hline Socios del Instituto Filarmónico & Socios fundadores \\
\hline \multirow{5}{*}{$\begin{array}{l}\text { Aguirre y Estarrona, Isaac Albéniz, Manuel } \\
\text { Álvarez, Francisco Amato, Eduardo Ar- } \\
\text { güelles, Valentin Arín, José Benaiges, Justo } \\
\text { Blasco Compans, Luis Borrero, Tomás } \\
\text { Bretón, Apolinar Brull, Melecio Brull, } \\
\text { Salvador Bustamante, Natividad Cabañas, } \\
\text { Enrique Calvist, Ernesto Calvist, Manuel } \\
\text { Calvo, José Campra, Ruperto Cancio, Cruz } \\
\text { Cerezo, Vicente Costa y Nogueras, Anto- } \\
\text { nio Cuéllar, Juan de Castro, Óscar de la } \\
\text { Cinna, Conde de Michelena, Rafael de } \\
\text { Pantis, Antonio Duque, José Erviti, } \\
\text { Casimiro Espino, Juan Fabré, Salvador } \\
\text { Feijas, Enrique Fernández Arbos, Cayetano } \\
\text { Fernández, Ricardo Fernández, Dionisio } \\
\text { Fernández, Rafael Gálvez, Luis García, } \\
\text { Isidoro García Rosetti, Manuel García, } \\
\text { Javier Giménez Delgado, Francisco Gon- } \\
\text { źlez, Andres Goñi, Benito Hernández de la } \\
\text { Cruz, Manuel Jiménez, Enrique Jordá, } \\
\text { Florencio Larrauri, Luis Lucientes, Manuel } \\
\text { Lucientes, Emilio Mageste, Vicente Mañas, } \\
\text { Pantaleón Martínez, Gregorio Mateos, } \\
\text { Rosario Mendizábal, José Mondéjar y } \\
\text { Mendoza, Manuel Moral, Guillermo Mor- } \\
\text { phy, Antonio Oller, Francisco Oltra, Ri- } \\
\text { cardo Oyanarte, Cándido Peña, Ángel } \\
\text { Quílez, Antonio Quintana, Josefa Rabadán, } \\
\text { Ricardo Rodríguez y Jiménez, Agustín } \\
\text { Rubio, Fermín Ruiz de Escobés, Carlos } \\
\text { Saco del Valle, Luis Samaniego, Francisco } \\
\text { Saper, Emilio Serrano, Alfonso Sotillo, José } \\
\text { Torá, Antonio Trueba, Vicenta Tormo, } \\
\text { Pedro Urrutia, José Valderrama, Joaquín } \\
\text { Valverde, José Varela Silvari, Pilar Vecín de } \\
\text { Saco, Napoleón Verger, Tito Verger, Casto } \\
\text { Vilar, Francisco Vidal y B. Vidal }\end{array}$} & $\begin{array}{l}\text { Apolinar Brull, Melecio Brull, Natividad } \\
\text { Cabañas, Ruperto Cancio, Juan de Castro, } \\
\text { Cruz Cerezo, Florencio Larrauri, Ramón } \\
\text { Michelena, Ricardo Oyanarte, Luis Ra- } \\
\text { mos, Agustín Rubio, Carlos Saco del Valle, } \\
\text { Luis Samaniego, Emilio Serrano, Antonio } \\
\text { Trueba, Pantaleón Martínez, Pedro de } \\
\text { Urrutia, Pilar Vecín del Saco y Napoleón } \\
\text { Verger }\end{array}$ \\
\hline & Socios honorarios \\
\hline & Pablo \\
\hline & Profesores honorarios \\
\hline & $\begin{array}{l}\text { Eduardo Argüelles, José Benaiges, Luis } \\
\text { Borrero, señores Bretón, Luis García, } \\
\text { Ernesto Calvist, Oscar de la Cinna, Vicente } \\
\text { Costa y Nogueras, Juan Fabre, Salvador } \\
\text { Feijas, Dionisio Fernández, Rafael Gálvez, } \\
\text { Andres Goñi, Isidoro García Rossetti, } \\
\text { Benito Hernández de la Cruz, Manuel } \\
\text { Jiménez, Emilio Magesté, Vicente Mañas, } \\
\text { Matas, Gregorio Mateos, Josefa Rabadán, } \\
\text { Tito Verger, B. Vidal }\end{array}$ \\
\hline
\end{tabular}


Cuadro 2. Instituto Filarmónico (IF): Materias y Profesores (Elaborada a partir de las Memorias del Instituto Filarmónico y de datos obtenidos en Federico Sopeña: Historia crítica del Conservatorio de Madrid, Madrid, 1967).

\begin{tabular}{|c|c|c|c|}
\hline Asignatura & \begin{tabular}{|l|} 
Profesor/a \\
\end{tabular} & Año & Observaciones \\
\hline \multirow{8}{*}{ Solfeo } & Natividad Cabañas & 1883 a 1885 & Socio fundador IF. En 1885 ausente \\
\hline & Pilar Vecín de Saco & 1883 a 1885 & Socio fundador IF. En 1885 ausente \\
\hline & Rosario Mendizábal & 1883-1884.. & \\
\hline & Ricardo Oyanarte & $\begin{array}{l}1883-1884 \text { a } \\
1885-1886 \ldots\end{array}$ & $\begin{array}{l}\text { Socio fundador IF. } \\
\text { Primer premio de piano en el Conservatorio. }\end{array}$ \\
\hline & Cayetano Fernández & $1883-1884 \ldots$ & \\
\hline & Enrique Calvist & 1883-1884... & Director banda de alarbaderos \\
\hline & Luis Lucientes & $1883-1884 .$. & Sociedad de Conciertos \\
\hline & Florencio Larrauri & $\begin{array}{l}1883-1884, \\
1885-1886 \ldots\end{array}$ & $\begin{array}{l}\text { Socio fundador IF. Profesor auxiliar 1899-1900 en } \\
\text { el Conservatorio. }\end{array}$ \\
\hline \multirow{8}{*}{ Piano } & Antonia Fdez. Pulem & $1884-1885$ & \\
\hline & Isaac Albéniz & $\begin{array}{l}1883 \text { a } 1886 \\
1886 \text { a } 1889 ?\end{array}$ & 1889 viaja a París, luego Inglaterra \\
\hline & Apolinar Brull & 1883 a 1888 & $\begin{array}{l}\text { Socio fundador IF. En } 1889 \text { es Maestro- } \\
\text { concertador de la Compañía cómico lírica }\end{array}$ \\
\hline & Ángel Quílez & $1883-1884$ & Ex-socio fundador desde 1884 \\
\hline & Cándido Peña & $\begin{array}{l}1883-1884, \\
1886-1887, \ldots\end{array}$ & Socio fundador IF \\
\hline & Antonio Trueba & $\begin{array}{l}1884-1885 \text { a } \\
1887-1888, \ldots\end{array}$ & $\begin{array}{l}\text { Socio fundador IF } \\
\text { Primer premio en Composición } 1881\end{array}$ \\
\hline & Cruz Cerezo & $\begin{array}{l}1884-1885 \\
1885-1886\end{array}$ & $\begin{array}{l}\text { Primer premio piano 1881. Se establece en } \\
\text { América en 1886. Éxito como concertista. }\end{array}$ \\
\hline & Melecio Brull & $\begin{array}{l}1884-1885, \text { a } \\
1886-1887 \ldots\end{array}$ & $\begin{array}{l}\text { Escribe Lecciones autografiadas para repentizar. } \\
\text { Aux. Conservatorio 1889, Honorario } 1890\end{array}$ \\
\hline \multirow{3}{*}{ Violín } & Enrique Fdez. Arbós & 1883-1884 & $\begin{array}{l}\text { Abril de } 1884 \text { abandona España. } \\
\text { Numerario Conservatorio } 12 \text { de julio } 1888\end{array}$ \\
\hline & Manuel Pérez & $1884-1885 \ldots$ & $\begin{array}{l}\text { Pertenece a la Sociedad de Cuartetos y Sociedad de } \\
\text { Conciertos/director del Teatro real (1883-1888; } \\
\text { 1890-1894) }\end{array}$ \\
\hline & Pedro de Urrutia & $\begin{array}{l}1884-1885 a \\
1887-1888\end{array}$ & $\begin{array}{l}\text { Profesor del Conservatorio } 1873 \text { (cesó en 1874); } \\
\text { Sociedad de Conciertos, / director del Teatro Real } \\
\text { (1885-1886; 1887-1890; 1894-1902) }\end{array}$ \\
\hline \multirow{2}{*}{ Violonchelo } & Agustín Rubio & $\begin{array}{l}1884-1885 \\
1886-1887\end{array}$ & Ausente en 1885 temporalmente \\
\hline & Manuel Calvo & $\begin{array}{l}1884-1885 \\
1885-1886 \ldots\end{array}$ & $\begin{array}{l}\text { Miembro de la Sociedad de Conciertos y de la } \\
\text { Orquesta del Teatro Real }\end{array}$ \\
\hline Contrabajo & Juan de Castro & 1884 a 1887 & Miembro Sociedad de conciertos \\
\hline Arpa & Vicenta Tormo & $\begin{array}{l}\text { 1883-1884, } \\
1886-1887\end{array}$ & $\begin{array}{l}\text { Primera arpista del Teatro Real y de la Sociedad de } \\
\text { Conciertos }\end{array}$ \\
\hline Flauta & $\begin{array}{l}\text { Francisco González } \\
\text { Maestre }\end{array}$ & Desde 1884 & $\begin{array}{l}\text { Primer flauta de la Sociedad de Conciertos. } \\
\text { Profesor honorario del Conservatorio en } 1885 . \\
\text { Profesor por oposición } 7 \text { de febrero } 1888 \\
\end{array}$ \\
\hline Clarinete & José Campra & Desde1883 & \\
\hline Oboe & $\begin{array}{l}\text { Fermín Ruiz de } \\
\text { Escobés }\end{array}$ & Desde 1883 & 21 de enero1888 \\
\hline
\end{tabular}




\begin{tabular}{|c|c|c|c|}
\hline Fagot & Manuel Lucientes & Desde 1883 & Sociedad de Conciertos. Cuerpo de Alabarderos \\
\hline Trompa & Alfonso Sotillo & $1886-1887$ & Sociedad de Conciertos \\
\hline Cornetín & Antonio Duque & Desde 1883 & Sociedad de Conciertos \\
\hline Trombón & José Valderrama & $1886-1887$ & Oposita conservatorio dic. 1888 \\
\hline \multirow{2}{*}{ Canto } & Napoleón Verger & 1883 a 1889 & Socio fundador IF \\
\hline & Antonio Trueba & 1883 a 1889 & Socio fundador IF \\
\hline \multirow[t]{3}{*}{ Armonía } & Ruperto Cancio I & $\begin{array}{l}1883-1884 \\
1885-1886\end{array}$ & $\begin{array}{l}\text { Socio fundador IF } \\
\text { Escribe Lecciones Teórico-Prácticas de Armonía } \\
\text { Elemental. } 1879\end{array}$ \\
\hline & José Erviti & $1884-1885 \ldots$ & $\begin{array}{l}\text { Primer premio armonía } \\
\text { Prof. Conservatorio } 1875\end{array}$ \\
\hline & Varela Silvari & $1887-1888 \ldots$ & $\begin{array}{l}\text { Agregado al Claustro en } 1886 \text {. Escribe: Teoría de la } \\
\text { música, Manual teórico-práctico de armonía, y Formulario } \\
\text { armónico }\end{array}$ \\
\hline \multirow{2}{*}{ Composición } & Emilio Serrano I & 1883 a 1885 & Desde 1885-1888 ausente (pensionado) \\
\hline & Casimiro Espino II & $1883-1884 \ldots$ & \\
\hline \multirow[t]{2}{*}{ Francés } & Carlos Saco del Valle & 1883 a 1885 & $\begin{array}{l}\text { Socio Fundador IF. Secretario IF hasta dic. de } \\
\text { 1885. Ausente en } 1885 \\
\text { Numerario Conservatorio } 1914\end{array}$ \\
\hline & Francisco Amato & $\begin{array}{l}1883-1884 \text { a } \\
1886-1887\end{array}$ & \\
\hline \multirow{2}{*}{ Italiano } & Casto Vilar & $1883-1884$ & \\
\hline & Tito Verger & $1886-1887$ & \\
\hline $\begin{array}{l}\text { Literatura } \\
\text { musical }\end{array}$ & Joaquín Valverde & $\begin{array}{l}1884,1885, \\
1886\end{array}$ & \\
\hline \multirow{3}{*}{ Clase popular } & Justo Blasco Compans & 1884 a 1889 & $\begin{array}{l}\text { 1888/89 maestro de canto en el colegio San } \\
\text { Antonio de los Portugueses. 15-05-1892 Profesor } \\
\text { del Conservatorio } \\
\text { Escribe: Escuelas práctica para la emisión de la voz } \\
\text { publicado por la casa Romero en sep. de } 1889 \text {. } \\
\text { Vocalización para tiple, para el primer año, vocalización } \\
\text { para tenor, vocalización para contralto o bajo }\end{array}$ \\
\hline & $\begin{array}{l}\text { Antonio Oller y } \\
\text { Biosca }\end{array}$ & $\begin{array}{l}1883-1884 \\
1884-1885 \ldots\end{array}$ & $\begin{array}{l}\text { Cantante Capilla Real, Maestro de capilla de } \\
\text { Igualada y Sabadell, Maestro director de la escolanía } \\
\text { de Monserrat. Maestro al piano y organista del } \\
\text { Teatro Real }\end{array}$ \\
\hline & Gregorio Mateos & $1884-1885 \ldots$ & Organista y maestro concertador del Teatro Real \\
\hline Declamación & Francisco Saper & $\begin{array}{l}1883-1884 \\
1884-1885 . . \\
\end{array}$ & Director de escena del Teatro Real \\
\hline
\end{tabular}


Cuadro 3. Plan general de enseñanza del Conservatorio/Instituto Filarmónico

\begin{tabular}{|c|c|c|}
\hline Asignaturas & Conservatorio & Instituto Filarmónico \\
\hline \multirow[t]{7}{*}{ Asignaturas } & $\begin{array}{l}\text { Solfeo, Piano, Violin, Violoncelo, Contrabajo, } \\
\text { Flauta, Clarinete, Oboe, Fagot, Cornetín } \\
\text { Trompa, Trombón, Arpa, Armonium, Organo. }\end{array}$ & $\begin{array}{l}\text { Solfeo, Piano, Violin, Violoncelo, } \\
\text { Contrabajo, Flauta, Clarinete, Oboe, } \\
\text { Fagot, Cornetín, Trompa, Trombón, } \\
\text { Arpa }\end{array}$ \\
\hline & Armonía & $\begin{array}{l}\text { Armonía } \\
\text { Acompañamiento y Transporte del } \\
\text { bajo numerado (1886) } \\
\end{array}$ \\
\hline & Composición & Composición \\
\hline & Mímica aplicada al canto & \\
\hline & $\begin{array}{l}\text { Canto } \\
\text { Declamación Lírica y Dramática }\end{array}$ & $\begin{array}{l}\text { Canto } \\
\text { Declamación } \\
\text { Clase popular (curso 1883-1884) } \\
\text { Clase de canto en español (a partir } \\
\text { curso 1884-1885) } \\
\text { Literatura musical (formación } \\
\text { repertorio dramático) }\end{array}$ \\
\hline & Italiano, Francés & Italiano, Francés \\
\hline & Conjunto vocal (1885) & $\begin{array}{l}\text { Conjunto vocal } \\
\text { Conjunto instrumental }\end{array}$ \\
\hline $\begin{array}{l}\text { Pruebas de } \\
\text { ingreso }\end{array}$ & $\begin{array}{l}\text { Examen o certificación: Saber leer y escribir } \\
\text { correctamente. Las cuatro operaciones } \\
\text { fundamentales de la aritmética. } \\
\text { Para canto: haber aprobado solfeo }\end{array}$ & Idem \\
\hline $\begin{array}{l}\text { Frecuencia } \\
\text { clases }\end{array}$ & Diarias, 2 h. cada dia, diferenciadas por sexo & $\begin{array}{l}\text { Mínimo, tres veces por semana, } \\
\text { diferenciadas por sexo }\end{array}$ \\
\hline $\begin{array}{l}\text { Enseñanza / } \\
\text { asignatura }\end{array}$ & $\begin{array}{l}\text { Sin límite por aula } \\
\text { No hay división enseñanzas elementales y } \\
\text { superiores } \\
\text { (Masificación, mezcla de niveles en las clases de } \\
\text { Solfeo) }\end{array}$ & $\begin{array}{l}\text { Solfeo: elemental } 20 \text { y superior } 12^{*} \\
\text { Instrumental: elemental } 12 \text { y superior } \\
6 \\
\text { Canto: máx. } 16 \\
\text { Composición: elemental } 8 \text { y sup. } 4 \\
\text { Armonía: elemental } 12 \text { y Sup. } 6 \\
\text { Tercer grado de perfecionamiento en } \\
\text { cualquier enseñanza: máx. } 2 \\
\end{array}$ \\
\hline Curso & 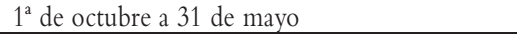 & $1^{\circ}$ de octubre a finales de junio, \\
\hline Exámenes & $\begin{array}{l}\text { No son públicos } \\
\text { Anuales: } 1^{a} \text { de junio }\end{array}$ & $\begin{array}{l}\text { Públicos y con tribunal } \\
\text { Trimestrales, semestrales, fin de } \\
\text { curso, } \\
\text { extraordinarios de septiembre }\end{array}$ \\
\hline
\end{tabular}

* Tasa límite por aula. 
Cuadro 4. Conciertos del Instituto Filarmónico

\begin{tabular}{|c|c|c|c|}
\hline Lugar & Fecha & Programa/Fuente & Intérpretes \\
\hline Salón Romero & 29-XII-1884 & $\begin{array}{l}\text { I Puritani de Bellini; Lucrecia de } \\
\text { Donizetti y Traviata de Verdi; A prima } \\
\text { de Morphy; La despedida del Cid de } \\
\text { Morphy por J. Blasco; Balada de } \\
\text { Chopin por Cruz Cerezo; Scherzo de } \\
\text { Gottchalk; Capricho de Mendelsshon } \\
\text { y Polaca de Chopin por Peña; Suite de } \\
\text { Bach; Sinfonia en SibM de Haydn y } \\
\text { Trío en SolM de Haydn }\end{array}$ & $\begin{array}{l}\text { Profesores: Verger, Blasco, Peña, } \\
\text { Cerezo. } \\
\text { Alumnas: Aldao y Oliva } \\
\text { Solistas de Madrid } \\
\text { Director: Tomás Bretón } \\
\text { Orquesta: profesores del Instituto } \\
\text { Filarmónico } \\
\text { Cámara: Urrutia (vi), Calvo (vc) y } \\
\text { Elvira Pérez (pi) }\end{array}$ \\
\hline Salón Romero & 7-I-1885 & No consta & Verger \\
\hline $\begin{array}{l}\text { Teatro Real } \\
\text { (Homenaje a } \\
\text { Verger) }\end{array}$ & III- 1885 & $\begin{array}{l}\text { Rossini, Verdi, Mozart, Gounod, } \\
\text { Cimarosa y Corti. } \\
\text { Quinteto de Cossi fan tutte de } \\
\text { Mozart; Tarantella de Gottchalk }\end{array}$ & $\begin{array}{l}\text { Sras. Teodorini (Tiple), Pasqua } \\
\text { (contralto) y Oliva (alumna de } \\
\text { Verger) y los sres. Masini, el } \\
\text { barítono Baldelli, el bajo Rapp, } \\
\text { Pome, Peña ( piano), Verger, } \\
\text { Pérez (director y violín,), Pedro } \\
\text { Urrutia (violín) }\end{array}$ \\
\hline Salón Romero & $24-V I-1885$ & No conta & $\begin{array}{l}\text { Verger, Oliva, Aldao, Moreno, } \\
\text { Astigarraga, Vilamar, Lillio }\end{array}$ \\
\hline Casa de Verger & 10-II -1886 & $\begin{array}{l}\text { Obras líricas de Mozart, Donizetti, } \\
\text { Meyerbeer, Verdi y Gounod }\end{array}$ & $\begin{array}{l}\text { Verger y sus alumnas: Moreno, } \\
\text { Vereda, Bibiana Pérez, Aldao y } \\
\text { Paoli. Alumnos: Artigana, } \\
\text { Villamar, Lillio y Astigarraga. } \\
\text { Al piano: Trueba y Volpini } \\
\end{array}$ \\
\hline Salón Romero & 24-VI-1887 & $\begin{array}{l}\text { Terceto de Un ballo in maschera; } \\
\text { Lucrecia Borgia; Romanza de Roberto el } \\
\text { Diablo; El Trovador }\end{array}$ & $\begin{array}{l}\text { Verger y sus alumnos: Amalia } \\
\text { Pauli, Moreno Leante y el Sr. } \\
\text { Astigarraga }\end{array}$ \\
\hline Salón Romero & II-1888 & No consta & Verger \\
\hline Instituto (IF) & VI-1888 & No consta & Ana López Peñafiel \\
\hline Salón Romero & 24-VI-1888 & $\begin{array}{l}\text { Allegro de concierto de Weber para } \\
\text { piano; Le dernier amour de Gottchak; } \\
\text { Andante de Herz; Scherzo de } \\
\text { Mendelssohn. } \\
\text { En canto: La forza del destino, La } \\
\text { favorita, Fausto, cavatina de } \\
\text { Semiramide, dúo Puritani, Don Juan de } \\
\text { Mozart, Don carlos de Verdi, Ave } \\
\text { Maria de Marchet, vals de Dinorah, } \\
\text { rondó de la Sonambula }\end{array}$ & $\begin{array}{l}\text { Srta Cruz (piano) } \\
\text { Portales (piano), Sanz (tenor), } \\
\text { Portierra, Stas Larraz y Vega Rey. } \\
\text { Alumnos (superior de canto) de } \\
\text { Verger: Moreno (contralto), Srta. } \\
\text { Vereda, Sr. Cardona (bajo), Srta, } \\
\text { Romadera, Srta. López Peñafiel. } \\
\text { Profesores al piano acompañando } \\
\text { el canto: Trueba y Urrutia }\end{array}$ \\
\hline $\begin{array}{l}\text { Teatro Príncipe } \\
\text { Alfonso }\end{array}$ & $3-V-1888$ & $\begin{array}{l}\text { Fausto de Gounod por Bibiana Pérez } \\
\text { I Puritani de Bellini por Verger } \\
\text { Canciones de G. A. Béquer de Bretón } \\
\text { cantadas por Pérez, etc. }\end{array}$ & $\begin{array}{l}\text { Concierto vocal e instrumental } \\
\text { con la colaboración de la Sociedad } \\
\text { de Conciertos }\end{array}$ \\
\hline Salón Romero & 26-II -1889 & $\begin{array}{l}\text { La favorita, Sonambula, I lombardi, Don } \\
\text { Giovanni, Sonambula, Moisés, Rigoletto, } \\
\text { Fausto, Tarantella, Ti rapirei, Ernani, } \\
\text { Baciani Gigi (Serrano) }\end{array}$ & $\begin{array}{l}\text { Verger y alumnos: Aldao, Varela, } \\
\text { Cardona, Verger, Peña, } \\
\text { Romaguera, Carrión, Sanz, } \\
\text { Al piano: Serrano y Trueba }\end{array}$ \\
\hline $\begin{array}{l}\text { Centro de } \\
\text { Asturianos }\end{array}$ & 8 -VII-1887 & La favorita & Moreno y Sáez \\
\hline
\end{tabular}


Cuadro 5. Algunas actuaciones de los alumnos del IF, en el Teatro Real. (1886-1892)*

\begin{tabular}{|c|c|c|c|c|c|}
\hline Artista & 1886-87 & $1887-88$ & $1888-89$ & $1889-90$ & $1891-92$ \\
\hline $\begin{array}{l}\text { Bibiana } \\
\text { Pérez }\end{array}$ & $\begin{array}{l}\text { Guillermo } \\
\text { Tell de } \\
\text { Rossini(4) } \\
* *\end{array}$ & $\begin{array}{l}\text { Guillermo Tell } \\
\text { de Rossini (4); } \\
\text { Carmen de } \\
\text { Bizet (5) }\end{array}$ & $\begin{array}{l}\text { Norma de Bellini (1); } \\
\text { Carmen de Bizet (8); } \\
\text { L'étoile du nord de } \\
\text { Meyerbeer (8); Los } \\
\text { amantes de Teruel de } \\
\text { Bretón (Estreno 7); I } \\
\text { promessi sposi de Petrella }\end{array}$ & & \\
\hline $\begin{array}{l}\text { Vicente } \\
\text { Megía }\end{array}$ & & & $\begin{array}{l}\text { Los amantes de Teruel de } \\
\text { Bretón (7); Mefistofeles } \\
\text { de Arrigo Boito (5), } \\
\text { Semiramide de Rossini } \\
\text { (4) }\end{array}$ & & \\
\hline $\begin{array}{l}\text { Ignacio } \\
\text { Tabuyo }\end{array}$ & & & $\begin{array}{l}\text { Lohengrin de Wagner } \\
\text { (6); Il papa Martin de } \\
\text { Cagnoni (1); Giovanna } \\
\text { la Pazza de Emilio } \\
\text { Serrano (Estreno 5) }\end{array}$ & $\begin{array}{l}\text { Lucia di Lammermoor } \\
\text { de Donizetti (9); } \\
\text { Aida de Verdi (7); } \\
\text { La Gioconda de } \\
\text { Ponchielli (4); } \\
\text { Cavallería Rusticana } \\
\text { de Mascagni (5); } \\
\text { L'áfricaine de } \\
\text { Meyerbeer (6); } \\
\text { Crispino a la comare } \\
\text { de Ricci (3); Irene de } \\
\text { Otranto de Emilio } \\
\text { Serrano (Estreno 3) }\end{array}$ & $\begin{array}{l}\text { La Gioconda } \\
\text { de Ponchielli } \\
\text { (7); Rachel de } \\
\text { Antonio } \\
\text { Santamaría } \\
\text { (Estreno 2); } \\
\text { Aida de } \\
\text { Verdi (5); } \\
\text { L'Africaine de } \\
\text { Meyerbeer } \\
\text { (1); Edgar de } \\
\text { Puccini (3) }\end{array}$ \\
\hline $\begin{array}{l}\text { Araceli } \\
\text { Aponte }\end{array}$ & & & & & $\begin{array}{l}\text { Ernani de } \\
\text { Verdi (3) }\end{array}$ \\
\hline $\begin{array}{l}\text { Amalia } \\
\text { Paoli }\end{array}$ & & $\begin{array}{l}\text { No } \\
\text { especificado. } \\
\text { Fuente: } \\
\text { Programa } \\
\text { Teatro Real } \\
\text { (Archivo de } \\
\text { Almagro) } \\
\end{array}$ & & $\begin{array}{l}\text { No especificado. } \\
\text { Fuente: Programa } \\
\text { Teatro Real } \\
\text { (Archivo de } \\
\text { Almagro) }\end{array}$ & \\
\hline
\end{tabular}

*Según Programas Teatro Real (Archivo de Almagro) y J. Turina Gómez: Historia del Teatro Real, Madrid, Alianza, 1997. ***úmero de funciones

Recibido: 9-6-2016

Aceptado: 29-8-2016 